\title{
Three-dimensional dynamics of hydrous thermal-chemical plumes in oceanic subduction zones
}

\section{Guizhi Zhu}

Department of Geoscience, ETH Zurich, CH-8092 Zurich, Switzerland (guizhi.zhu@erdw.ethz.ch)

\author{
Taras V. Gerya \\ Department of Geoscience, ETH Zurich, CH-8092 Zurich, Switzerland
}

Also at Geology Department, Moscow State University, 119899 Moscow, Russia

\section{David A. Yuen}

Department of Geology, University of Minnesota, Minneapolis, Minnesota 55455-0219, USA

\section{Satoru Honda}

Earthquake Research Institute, University of Tokyo, Tokyo 113-0032, Japan

\section{Takeyoshi Yoshida}

Institute of Mineralogy, Petrology and Economic Geology, Graduate School of Science, Tohoku University, Sendai 980-8578, Japan

\section{James A. D. Connolly}

Department of Geoscience, ETH Zurich, CH-8092 Zurich, Switzerland

[1] Hydration and partial melting along subducting slabs can trigger Rayleigh-Taylor-like instabilities. We use 3-D petrological-thermomechanical numerical simulations to investigate small-scale convection and hydrous, partially molten, cold plumes formed in the mantle wedge in response to slab dehydration. The simulations were carried out with the I3ELVIS code, which is based on a multigrid approach combined with marker-in-cell methods and conservative finite difference schemes. Our numerical simulations show that three types of plumes occur above the slab-mantle interface: (1) finger-like plumes that form sheet-like structure parallel to the trench, (2) ridge-like structures perpendicular to the trench, and (3) flattened wavelike instabilities propagating upward along the upper surface of the slab and forming zigzag patterns parallel to the trench. The viscosity of the plume material is the main factor controlling the geometry of the plumes. Our results show that lower viscosity of the partially molten rocks facilitates the Rayleigh-Taylorlike instabilities with small wavelengths. In particular, in low-viscosity models $\left(10^{18}-10^{19} \mathrm{~Pa} s\right)$ the typical spacing of finger-like plumes is about $30-45 \mathrm{~km}$, while in high-viscosity models $\left(10^{20}-10^{21} \mathrm{~Pa} \mathrm{~s}\right)$ plumes become rather sheet-like, and the spacing between them increases to $70-100 \mathrm{~km}$. Water released from the slab forms a low-viscosity wedge with complex 3-D geometries. The computed spatial and temporal pattern of melt generation intensity above the slab is compared to the distribution and ages of volcanoes in the northeast Japan. Based on the similarity of the patterns we suggest that specific clustering of volcanic activity in this region could be potentially related to the activity of thermal-chemical plumes. 
Components: 9646 words, 8 figures, 4 tables.

Keywords: subduction zone; 3-D thermal-chemical plumes; Japanese volcanism.

Index Terms: 8170 Tectonophysics: Subduction zone processes (1031, 3060, 3613, 8413); 8120 Tectonophysics: Dynamics of lithosphere and mantle: general (1213); 8160 Tectonophysics: Rheology: general $(1236,8032)$.

Received 13 May 2009; Revised 10 August 2009; Accepted 22 September 2009; Published 13 November 2009.

Zhu, G., T. V. Gerya, D. A. Yuen, S. Honda, T. Yoshida, and J. A. D. Connolly (2009), Three-dimensional dynamics of hydrous thermal-chemical plumes in oceanic subduction zones, Geochem. Geophys. Geosyst., 10, Q11006, doi:10.1029/2009GC002625.

\section{Introduction}

[2] Although detailed numerical modeling of subduction zone processes is typically two-dimensional, along-trench variations in subduction zone magmatism [Honda and Yoshida, 2005; Honda et al., 2007; Tamura et al., 2002; Zhao et al., 2002], seismic data [e.g., Tamura et al., 2002; Zhao et al., 2002, 2009] demonstrate that subduction is inherently threedimensional (3-D). This 3-D character has been explored with thermomechanical models [e.g., Stegman et al., 2006; Honda and Saito, 2003; Honda et al., 2002, 2007; Lee and King, 2009]. Here we expand on these studies by incorporating the effects of dehydration/hydration processes and water transport above slabs [Gerya and Yuen, 2003b; Gorczyk et al., 2006] in a 3-D petrological-thermomechanical model for intraoceanic subduction.

[3] Dehydration of subducting slabs and hydration of the overlying mantle wedges are key processes controlling magmatic activity in subduction zones [Stern, 2002; van Keken et al., 2002; van Keken and King, 2005].The process has been investigated from geophysical [Fluck et al., 2003; Zhao et al., 2002], numerical [Arcay et al., 2005; Davies and Stevenson, 1992; Gerya et al., 2006; Nikolaeva et al., 2008], analog [Poli and Schmidt, 1995; Schmidt and Poli, 1998], and geochemical [Ito and Stern, 1986; Sajona et al., 2000] perspectives. Despite the progress in understanding mantle wedge processes, detailed thermal structure and melting patterns above slabs are still puzzling. Particularly, the relative importance of slab melting [e.g., Keleman et al., 2004; Nikolaeva et al., 2008] versus melting induced by simple thermal convection [Behn et al., 2007; Honda and Saito, 2003; Honda et al., 2002, 2007] and/or thermal-chemical plumes (diapirs) [Gerya and Yuen, 2003b; Gerya et al., 2004c; Gorczyk et al., 2007b; Hall and Kincaid, 2001; Manea et al., 2005; Obata and Takazawa, 2004] to melt production in volcanic arcs is not well understood. For example, as discussed by Kimura and Yoshida [2006], Quaternary lavas from NE Japan arc show geochemical evidence of mixing between mantle-derived basalts and crustal melts at the magmatic front, whereas significant crustal signals are not detected in the rear-arc lavas. Honda et al. [2007] also analyzed the spatial distribution of volcanism in the northeast Honshu arc, and found that it exhibits several "flip-flopped" clusters elongated nearly perpendicular to the arc and the possible migration of volcanism from the back-arc side to the volcanic front side. Such notable magmatic variability requires further insight from 3-D numerical modeling.

[4] Honda and coworkers [Honda and Saito, 2003; Honda et al., 2002; Honda and Yoshida, 2005; Honda et al., 2007] proposed the development of small-scale convection for low enough viscosity in the low-viscosity wedge (LVW) [Billen and Gurnis, 2001; Conder and Wiens, 2007; Honda and Saito, 2003; Honda et al., 2002; Honda and Yoshida, 2005] and suggested that small-scale convection is likely to occur when the viscosity of the LVW is $<10^{19} \mathrm{~Pa} \mathrm{~s}$, and that a roll (finger)-like pattern of hot (upwellings) and cold (downwellings) anomalies emerges in the mantle wedge above the subducting slab [Honda and Yoshida, 2005; Honda et al., 2007]. But only 2-D petrological-thermomechanical models with water transport and melting in subduction zones have been used to study (1) spontaneous formation of a LVW by hydration of the mantle wedge [Arcay et al., 2005, 2006], (2) growth dynamics of diapiric structures ("cold plumes") above the subducting slab [Gerya and Yuen, 2003b; Gorczyk et al., 2007a, 2007b], and (3) variation in seismic velocity beneath volcanic arcs [Gerya et al., 2006; Nakajima and Hasegawa, 2003a, 2003b].

[5] In this study, we develop a 3-D petrologicalthermomechanical model of intraoceanic subduction. The numerical code, I3ELVIS, is based on 
Table 1. Model Rock Composition ${ }^{\mathrm{a}}$

\begin{tabular}{|c|c|c|c|c|}
\hline & Sediment & $\begin{array}{c}\text { Upper } \\
\text { Oceanic Crust } \\
\text { (Altered Basalt) }\end{array}$ & $\begin{array}{l}\text { Lower } \\
\text { Oceanic Crust } \\
\text { (Gabbro) }\end{array}$ & $\begin{array}{c}\text { Mantle } \\
\text { (Peridotite) }\end{array}$ \\
\hline $\mathrm{SiO}_{2}$ & 61.10 & 47.62 & 53.49 & 45.55 \\
\hline $\mathrm{Al}_{2} \mathrm{O}_{3}$ & 12.43 & 14.48 & 14.07 & 4.03 \\
\hline $\mathrm{FeO}$ & 5.43 & 10.41 & 6.86 & 7.47 \\
\hline $\mathrm{MgO}$ & 2.59 & 6.92 & 12.07 & 37.42 \\
\hline $\mathrm{CaO}$ & 6.21 & 13.39 & 10.73 & 3.18 \\
\hline $\mathrm{Na}_{2} \mathrm{O}$ & 2.54 & 2.15 & 1.22 & 0.33 \\
\hline $\mathrm{K}_{2} \mathrm{O}$ & 2.13 & 0.58 & 0.09 & 0.03 \\
\hline $\mathrm{H}_{2} \mathrm{O}$ & 7.60 & 2.78 & 1.47 & 1.98 \\
\hline
\end{tabular}

${ }^{\mathrm{a}}$ Unit is wt \%. Sediment is the GlOSS average [Plank and Langmuir, 1998]; basalt is an average for the upper $500 \mathrm{~m}$ of the igneous section of the oceanic crust [Staudigel et al., 1989]; gabbro is a synthetic composition for the gabbroic section of the oceanic crust [Behn and Kelemen, 2003], modified to contain up to $1.5 \mathrm{wt} \%$ water to represent the effects of lower crustal hydrothermal alteration [Carlson, 2001]; and peridotite is the LOSIMAG composition [Morris and Hart, 1986] chosen to represent mantle peridotite. The compositions have been simplified by the omission of minor elements such $\mathrm{Mn}, \mathrm{P}, \mathrm{Ti}$, and $\mathrm{Cr}$ and the assumption that all $\mathrm{Fe}$ is ferrous; additionally, $\mathrm{CO}_{2}$ has been removed from the GLOSS sediment composition.

finite differences schemes and marker-in-cell techniques combined with multigrid approach, which is a new additional feature to the previous I2ELVIS code in 2-D [Gerya and Yuen, 2007]. The model includes a spontaneously bending retreating slab with a free surface as well as phase transformations and water transport [Nikolaeva et al., 2008]. We focus in particular on 3-D effects of hydration and melting of the mantle wedges including variations in geometries and patterns of hydrous thermalchemical upwellings ("cold plumes") formed above the slab. A possible application of our 3-D numerical study to natural magmatic phenomena is to compare numerical results with arc Quaternary volcanic activities along the Northeast Japanese arc.

\section{Numerical Model}

\subsection{Initial and Boundary Conditions}

[6] The present 3-D model as a reference model is a retreating slab intraoceanic subduction model [Nikolaeva et al., 2008] including four major rock compositions (Table 1). The spatial domain is a $200 \mathrm{~km}$ deep box that is $808 \mathrm{~km}$ long orthogonal to the subduction zone and $200 \mathrm{~km}$ wide. This domain is resolved by $405 \times 101 \times 101$ grid points with 30-50 million randomly distributed markers. The oceanic crust is represented by a $3 \mathrm{~km}$ thick upper layer of hydrothermally altered basalt above a $5 \mathrm{~km}$ thick gabbroic section, and the mantle consists of anhydrous peridotite (Figure 1a). The oceanic crust does not include sediments, but sediments spontaneously fill the trench after its depth reaches $8 \mathrm{~km}$ in order to mimic the natural geological phenomena.

[7] In the models, subduction is initiated along a prescribed weak fracture zone separating oceanic plates of different ages [Hall and Kincaid, 2001]. This zone is $30 \mathrm{~km}$ wide and $30 \mathrm{~km}$ thick and continues along the plate boundary. It consists of mantle rocks with wet olivine rheology [Ranalli, 1995] and high pore fluid pressure resulting in the low plastic strength of $1 \mathrm{MPa}$. During subduction this zone is replaced by weak subducted crustal rocks (basalts and sediments) and hydrated mantle, creating favorable conditions for a retreating onesided subduction [Gerya et al., 2008]. The initial thermal structures for both oceanic plates correspond to their imposed ages (1 and $70 \mathrm{Ma}$ for the left and right plates, respectively) with an oceanic geotherm [Turcotte and Schubert, 2002]. The thermal boundary conditions are constant temperature $(273 \mathrm{~K})$ at the upper boundary, thermally insulated vertical boundaries, and a heat flux boundary condition at the bottom of the model [Gorczyk et al., 2007b]. An external constant temperature condition simulating an additional mantle volume present below the bottom of the model is implemented by using the following relation: $\partial T / \partial z=$ $\left(T_{\text {external }}-T\right) / \Delta z_{\text {external } T}$, where $T_{\text {external }}=1700 \mathrm{~K}$ is the temperature at the external thermal boundary, $\Delta z_{\text {externalT }}=200 \mathrm{~km}$. This condition allows variation of both temperatures and heat fluxes at the lower boundary in response to subduction.

[8] No plate velocity is applied in our model. The velocity boundary conditions are free-slip, except for the lower boundary, which is permeable in vertical direction [Gorczyk et al., 2007b], and no slip for right boundary. Infinite-like external freeslip conditions [Burg and Gerya, 2005] along this boundary imply that the free-slip condition is satisfied at an external mechanical boundary located at depth $(2000 \mathrm{~km})$ below the model bottom. The external free-slip condition, which is similar to usual free-slip condition, allows global conservation of mass in the computational domain and is implemented by the following limitation for velocity components at the lower boundary:

$$
\partial v_{x} / \partial x=0 ; \quad \partial v_{z} / \partial z=-v_{z} / \Delta z_{\text {externalv }},
$$

where $\Delta z_{\text {externalV }}=2000 \mathrm{~km}$ is the vertical distance from the bottom of the model to the external mechanical boundary where free slip is satisfied. 

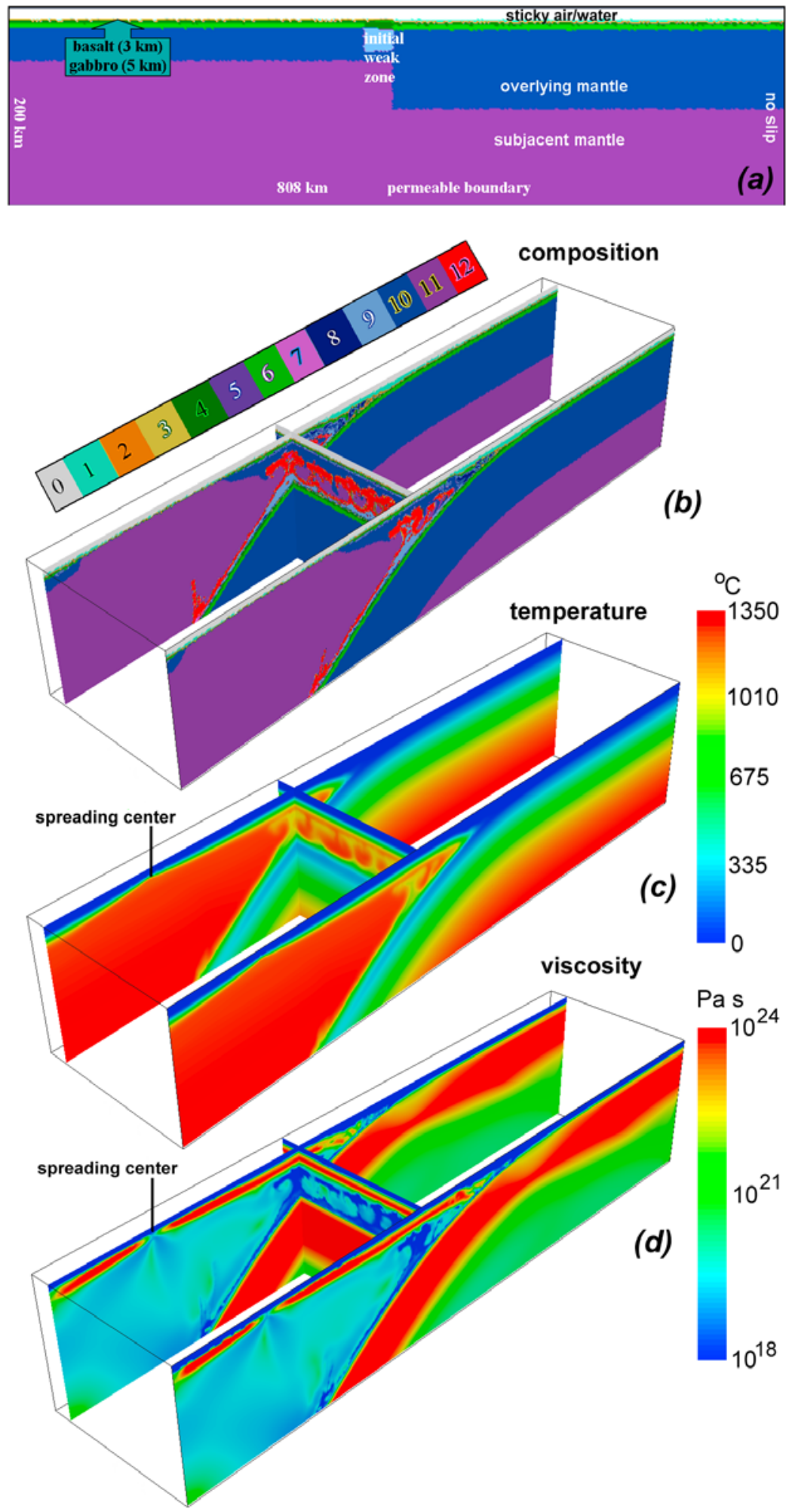

Figure 1. (a) Initial configuration and boundary conditions of numerical model for lithospheric/upper mantle section and details of the (b) composition, (c) temperature, and (d) viscosity fields for the $200 \mathrm{~km}$ wide reference case at $2.64 \mathrm{Ma}$ (model fta in Table 4). Colors for composition field are numbered as follows: 0 , air; 1, seawater; 2 and 3 , sediments ( 2 indicates solid, and 3 indicates molten); 4 and 5, basaltic crust (4 indicates solid, and 5 indicates molten); 6 and 7, gabbroic crust (6 indicates solid, and 7 indicates molten); 8 , sepentinized mantle; 9 , solid hydrated mantle; 10, dry lithospheric mantle; 11, dry asthenospheric mantle; 12, partially molten hydrated mantle. 
[9] The slab's width is assumed infinite in our model. During simulation the computational model domain with an $808 \mathrm{~km}$ width moves along the slab from left to right together with the retreating trench. Additional slab and mantle sections are provided from the right side of the model. We also ensure that the spreading center in response to the cooling and extension of the young plate on the left does not move out of the computational domain. This is achieved by placing a $100 \mathrm{~km}$ wide zone along the left boundary in which plastic strength of the mantle decreases linearly outward (i.e., $\sin (\varphi)$ decreases from 0.6 to 0.1 , where $\varphi$ is a friction angle, Table 2).

[10] The top surface of the oceanic crust is calculated dynamically as an essentially internal free surface by using a $10 \mathrm{~km}$ thick buffer layer of "sticky air" [Gerya and Yuen, 2003a; Schmeling et al., 2008]. It has low viscosity $\left(10^{18} \mathrm{~Pa} \mathrm{~s}\right)$ and density $\left(1 \mathrm{~kg} / \mathrm{m}^{3}\right.$ for the atmosphere, $1000 \mathrm{~kg} / \mathrm{m}^{3}$ for seawater prescribed in the weak layer below $\mathrm{z}=8 \mathrm{~km}$ water level). The large viscosity contrast caused by these low-viscosity boundary layers minimizes shear stresses $\left(<10^{4} \mathrm{~Pa}\right)$ at the top of the solid portion of the model [Burg and Gerya, 2005].

\subsection{Petrological-Thermochemical Model}

[11] Mineral phase transformation, such as dehydration reactions and melting, can affect the physical properties of rocks during the subduction process. Here we use a petrological-thermomechanical numerical modeling approach [Gerya et al., 2004b, 2006; Nikolaeva et al., 2008; Ueda et al., 2008] with all in situ rock properties including effective density, isobaric heat capacity, thermal expansion, adiabatic and latent heating as well as equilibrium water and melt content. All these rock properties are calculated for the Lagrangian rock markers at every time step based on Gibbs free energy minimization [Connolly and Petrini, 2002; Connolly, 2005] as a function of the local pressure, temperature and rock composition (Table 2). In particular, the in situ rock density is interpolated for every marker at each time step from the look-up density tables (in P-T space) precomputed with PERPLE_X program for the four rock compositions (Table 1). More details on the computation of various in situ rock properties for thermomechanical models are given by Vasilyev et al. [2004].

[12] Thermodynamics properties of fluids, melts, and minerals for this calculation are taken from an internally consistent thermodynamics database (Table 3). In the model, water is expelled from the subducted oceanic crust as a consequence of both dehydration reactions and compaction. The additional connate water content of the basaltic and sedimentary crust is assumed as a linear function of depth.

$$
X_{H_{2} O(p)}(w t . \%)=X_{H_{2} O(p 0)}(1-\Delta z / 75)
$$

where $X_{H_{2} O(p 0)}=2$ wt.\% is the connate water content at the surface, $\Delta z(\mathrm{~km})$ is the depth below the surface in $\mathrm{km}(0-75 \mathrm{~km})$. The release of this water also mimics the effects of low-temperature $(\mathrm{T}<573 \mathrm{~K})$ reactions not included in our thermodynamic database. According to our model, water released from the slab creates a rheologically weak hydrated zone between the plates that ensures self-sustaining retreating subduction [Gerya et al., 2008]. To simulate the migration of water released by dehydration process, we use independently moving rock and fluid markers [Gorczyk et al., 2007a]. A fluid marker with respective water amount is generated and moves upward until it reaches a lithology that assimilates water, which can account for water transport. Following Nikolaeva et al. [2008] the velocity of water is computed as

$$
v_{x(\text { water })}=v_{x} ; \quad v_{y(\text { water })}=v_{y} ; \quad v_{z(\text { water })}=v_{z}-v_{z(\text { percolation })}
$$

where $z$ is the vertical coordinate pointing downward, $x$ and $y$ are the horizontal and lateral (along strike) coordinates, respectively; $v_{x}, v_{y}$ and $v_{z}$ indicate the local velocity of the mantle, $v_{z \text { (percolation })}=10 \mathrm{~cm} / \mathrm{yr}$, an assumed parameter [Gorczyk et al., 2007b; Peacock, 1990], characterizing the upward speed of free water through the mantle. The free water is consumed by hydration and melting reactions in the mantle. Consequently, the propagation of the hydration/melting front in the mantle wedge is limited by the availability of water. This propagation is thus related to the rate of subduction which brings water to depths [Gerya et al., 2002, 2006].

[13] The effective viscosities of mantle rocks are calculated as a function of temperature, pressure and strain rate (Table 3 ) by using experimentally determined dislocation-creep flow laws [Ranalli, 1995, Tables 10.1 and 10.3]. The viscosity of partially molten rocks was taken to be constant and the influence of this constant on model development was investigated.

\subsection{Governing Equations and Numerical Implementation}

[14] We use the following equations for the conservation of mass, momentum and energy, 


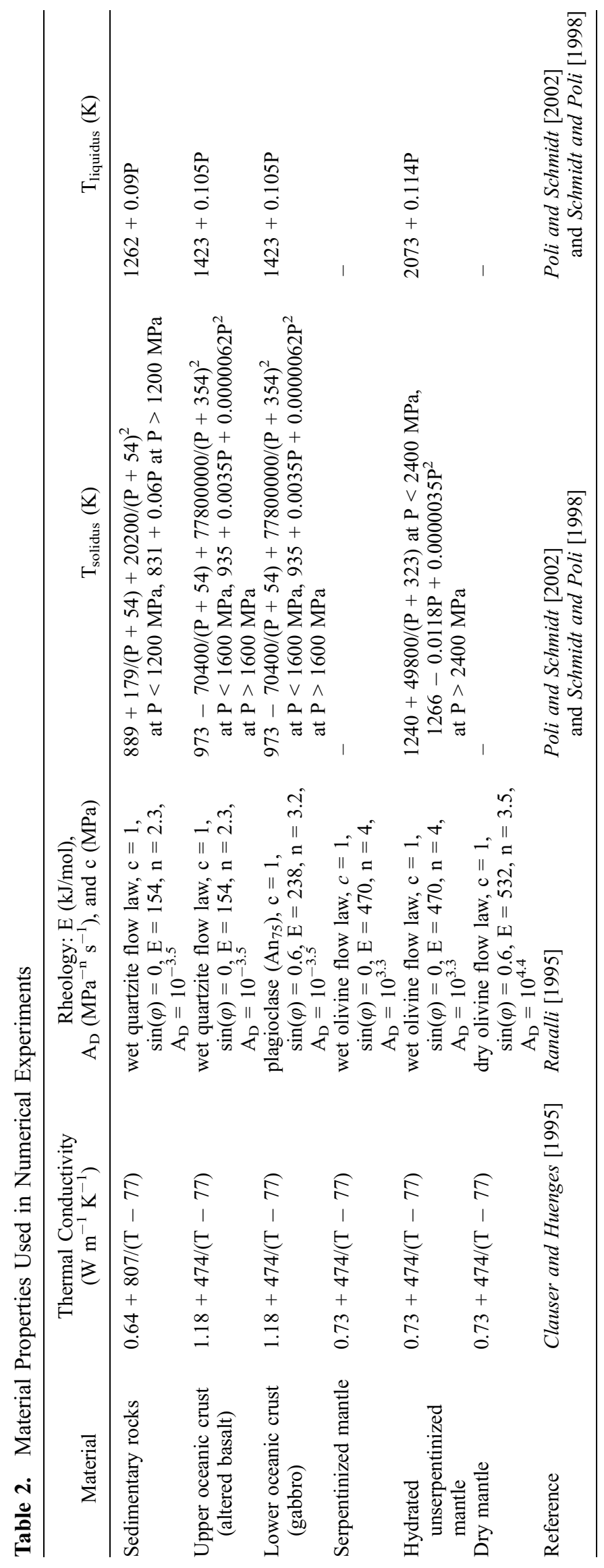


Table 3. Phase and Thermodynamic Data Sources ${ }^{\mathrm{a}}$

\begin{tabular}{|c|c|c|}
\hline Phase & Formula & Source \\
\hline Antigorite & $\mathrm{Mg}_{48 x} \mathrm{Fe}_{48(1-x)} \mathrm{Si}_{34} \mathrm{O}_{85}(\mathrm{OH})_{62}$ & Rupke et al. [2004] \\
\hline Clinoamphibole & $\begin{array}{l}\mathrm{Ca}_{2-2 w} \mathrm{Na}_{z+2 w} \mathrm{Mg}_{(3+2 y+z) x} \mathrm{Fe}_{(3+2 y+z)(1-x) \mathrm{Al}_{3}-y-w} \\
\mathrm{Si}_{7+w+y} \mathrm{O}_{22}(\mathrm{oH})_{2} w+y+z \leq 1\end{array}$ & Wei and Powell [2003] and White et al. [2003] \\
\hline Biotite & $\mathrm{KMg}_{(3-w) x} \mathrm{Fe}_{(3-w)(1-x)} \mathrm{Al}_{1+2 w} \overline{\mathrm{Si}}_{3 w} \mathrm{O}_{10}(\mathrm{OH})_{2} x+y \leq 1$ & Powell and Holland [1999] \\
\hline Chlorite & $\mathrm{Mg}_{(5-y+z) x} \mathrm{Fe}_{(5-y+z)(1-x)} \mathrm{Al}_{2(1+y-z)} \mathrm{Si}_{3-y+z} \mathrm{O}_{10}(\mathrm{OH})_{8}$ & Holland et al. [1998] \\
\hline Coesite & $\mathrm{SiO}_{2}$ & \\
\hline Clinopyroxene & $\mathrm{Na}_{1-y} \mathrm{Ca}_{\mathrm{y}} \mathrm{Mg}_{x y} \mathrm{Fe}_{(1-x) y} \mathrm{Al}_{y} \mathrm{Si}_{2} \mathrm{O}_{6}$ & Holland and Powell [1996] \\
\hline Fluid & $\mathrm{H}_{2} \mathrm{O}$ & Holland and Powell [1998] \\
\hline Garnet & $\mathrm{Fe}_{3 x} \mathrm{Ca}_{3 y} \mathrm{Mg}_{3(1-x-y)} \mathrm{Al}_{2} \mathrm{Si}_{3} \mathrm{O}_{12}$ & Holland and Powell [1998] \\
\hline Kyanite & $\mathrm{Al}_{2} \mathrm{SiO}_{5}$ & \\
\hline Lawsonite & $\mathrm{CaAl}_{2} \mathrm{Si}_{2} \mathrm{O}_{7}(\mathrm{OH})_{2} \cdot \mathrm{H}_{2} \mathrm{O}$ & \\
\hline Mica & $\mathrm{K}_{x} \mathrm{Na}_{1-x} \mathrm{Mg}_{y} \mathrm{Fe}_{z} \mathrm{Al}_{3-2(y+z)} \mathrm{Si}_{3+y+z} \mathrm{O}_{10}(\mathrm{OH})_{2}$ & Holland and Powell [1998] \\
\hline Melt & Na-Mg-Al-Si-K-Ca-Fe hydrous silicate melt & Ghiorso et al. [2002] \\
\hline Olivine & $\mathrm{Mg}_{2 x} \mathrm{Fe}_{2(1-x)} \mathrm{SiO}_{4}$ & Holland and Powell [1998] \\
\hline Orthopyroxene & $\mathrm{Mg}_{x(2-y)} \mathrm{Fe}_{(1-x)(2-y)} \mathrm{Al}_{2 y} \mathrm{Si}_{2-y} \mathrm{O}_{6}$ & Holland and Powell [1996] \\
\hline Plagioclase & $\mathrm{Na}_{x} \mathrm{Ca}_{1-x} \mathrm{Al}_{2-x} \mathrm{Si}_{2+x} \mathrm{O}_{8}$ & Newton et al. [1980] \\
\hline Sanidine & $\mathrm{Na}_{x} \mathrm{~K}_{1-x} \mathrm{AlSi}_{3} \mathrm{O}_{8}$ & Thompson and Hovis [1979] \\
\hline Stishovite & $\mathrm{SiO}_{2}$ & \\
\hline Talc & $\mathrm{Mg}_{(3-y) x} \mathrm{Fe}_{(3-y)(1-x)} \mathrm{Al}_{2 y} \mathrm{Si}_{4-y} \mathrm{O}_{10}(\mathrm{OH})_{2}$ & Holland and Powell [1998] \\
\hline
\end{tabular}

\footnotetext{
${ }^{\mathrm{a}}$ Unless indicated otherwise thermodynamic data were taken from Holland and Powell [1998] (revised 2002). The compositional variables $w, x$, $y$, and $z$ may vary between zero and unity and are determined as a function of pressure and temperature by free-energy minimization. Thermodynamic data for the iron end-member for antigorite solution was estimated as described by Rupke et al. [2004].
}

describing multiphase viscoplastic flow in Cartesian coordinate frame:

[15] The incompressible continuity equation

$$
\partial v_{x} / \partial x+\partial v_{y} / \partial y+\partial v_{z} / \partial z=0
$$

\section{The Stokes equations}

$$
\begin{aligned}
& \partial \sigma_{x x} / \partial x+\partial \sigma_{x y} / \partial y+\partial \sigma_{x z} / \partial z-\partial P / \partial x=0 \\
& \partial \sigma_{x y} / \partial x+\partial \sigma_{y y} / \partial y+\partial \sigma_{y z} / \partial z-\partial P / \partial y=0 \\
& \partial \sigma_{x z} / \partial x+\partial \sigma_{y z} / \partial y+\partial \sigma_{z z} / \partial z-\partial P / \partial z=\rho(P, T, C, M) g_{z}
\end{aligned}
$$

where

$$
\begin{aligned}
& \sigma_{x x}=2 \eta \dot{\varepsilon}_{x x}, \quad \sigma_{y y}=2 \eta \dot{\varepsilon}_{y y}, \quad \sigma_{z z}=2 \eta \dot{\varepsilon}_{z z}, \\
& \sigma_{x y}=2 \eta \dot{\varepsilon}_{x y}, \quad \sigma_{x z}=2 \eta \dot{\varepsilon}_{x z}, \quad \sigma_{y z}=2 \eta \dot{\varepsilon}_{y z}, \\
& \dot{\varepsilon}_{x x}=\partial v_{x} / \partial x, \quad \dot{\varepsilon}_{y y}=\partial v_{y} / \partial y, \quad \dot{\varepsilon}_{z z}=\partial v_{z} / \partial z \\
& \dot{\varepsilon}_{x y}=1 / 2\left(\partial v_{x} / \partial y+\partial v_{y} / \partial x\right), \quad \dot{\varepsilon}_{x z}=1 / 2\left(\partial v_{x} / \partial z+\partial v_{z} / \partial x\right), \\
& \dot{\varepsilon}_{y z}=1 / 2\left(\partial v_{y} / \partial z+\partial v_{z} / \partial y\right)
\end{aligned}
$$

The Lagrangian temperature equation includes latent heat effects of phase transformations in the crust and mantle by using effective values of heat capacity and (de)compression heating/cooling [Gerya et al., 2004a].

$$
\begin{aligned}
\rho C_{p}(D T / D t)= & \partial(k \partial T / \partial x) / \partial x+\partial(k \partial T / \partial y) / \partial y \\
& +\partial(k \partial T / \partial z) / \partial z+H_{r}+H_{P}+H_{s}
\end{aligned}
$$

$C_{p}=\left(\frac{\partial H}{\partial T}\right)_{P}$

$H_{P}=\left[1-\rho\left(\frac{\partial H}{\partial P}\right)_{T}\right] \frac{D P}{D t}$

$H_{s}=\sigma_{x x} \dot{\varepsilon}_{x x}+\sigma_{y y} \dot{\varepsilon}_{y y}+\sigma_{z z} \dot{\varepsilon}_{z z}+2 \sigma_{x y} \dot{\varepsilon}_{x y}+2 \sigma_{x z} \dot{\varepsilon}_{x z}+2 \sigma_{y z} \dot{\varepsilon}_{y z}$

where $x$ and $y$ are horizontal and lateral (along strike) coordinates, respectively; $z$ is vertical coordinate with the axis directed downward; $v_{x}, v_{y}$, and $v_{z}$ indicate the components of the velocity vector $\bar{v} ; t$ is time; $\sigma_{x x}, \sigma_{y y}, \sigma_{z z}, \sigma_{x y}, \sigma_{x z}, \sigma_{y z}$ are the components of the viscous deviatoric stress tensor in Pa; $\dot{\varepsilon}_{x x}, \dot{\varepsilon}_{y y}, \dot{\varepsilon}_{z z}, \dot{\varepsilon}_{x y}, \dot{\varepsilon}_{x z}, \dot{\varepsilon}_{y z}$ are the components of the strain rate tensor; $P$ is the pressure, $g_{z}=9.81 \mathrm{~m} / \mathrm{s}^{2}$ is the gravitational acceleration, $T$ is the temperature, and the density $\rho(P, T, C, M)$ depends explicitly on the temperature, the composition, and the equilibrium mineral composition [Gerya and Yuen, 2003b], $k(T, c)$ is the variable thermal conductivity [Clauser and Huenges, 1995], $C_{p}$ is the effective isobaric heat capacity, i.e., incorporating latent heat; $H$ is rock enthalpy; $H_{r}, H_{P}$ and $H_{s}$ denote radioactive heat production (Table 2), the 
energetic effect of isothermal (de)compression, and shear heating, respectively, in $\mathrm{W} \mathrm{m}^{-3}$. We note that we have employed the multigrid method described in the textbook [Gerya, 2009]. for solving the 3-D momentum equations (equation (2)), because of the memory considerations prevent the usage of the direct method.

[16] The viscosity of mantle rocks dependent on strain rate, pressure and temperature is defined in terms of deformation invariants [Ranalli, 1995] as:

$$
\eta_{\text {creep }}=\left(\dot{\varepsilon}_{\mathrm{II}}\right)^{(1-n) / 2 n} F\left(A_{D}\right)^{-1 / n} \exp \left(\frac{E_{a}+V_{a} P}{n R T}\right)
$$

where $\dot{\varepsilon}_{\text {II }}=1 / 2 \dot{\varepsilon}_{i j} \dot{\varepsilon}_{i j}$ is the second invariant of the strain rate tensor; $A_{D}, E_{a}, V_{a}$ and $n$ are experimentally determined dislocation-creep flow law (Table 2) parameters. $F$ is a nondimensional coefficient depending on the type of experiments on which the flow law is based. For example:

$$
F=\frac{2^{(1-n) / n}}{3^{(1+n) / 2 n}}
$$

for triaxial compression and

$$
F=2^{(1-2 n) / n}
$$

for simple shear.

[17] The ductile rheology together with a brittle/ plastic rheology yields an effective viscoplastic rheology. For this purpose the Mohr-Coulomb yield criterion [Ranalli, 1995] is implemented by a limiting creep viscosity, $\eta_{\text {creep }}$, as follows:

$$
\eta_{\text {creep }} \leq \frac{c+P \sin (\varphi)}{\left(4 \dot{\varepsilon}_{I I}\right)^{1 / 2}}
$$

where $P$ is the complete (nonlithostatic) pressure (i.e., the mean stress), $c$ is the cohesion (residual strength at $P=0$ ) and $\varphi$ is effective internal friction angle (Table 2). Assuming high pore fluid pressure in hydrated rocks [Gerya et al., 2008], the upper oceanic crust (basalts, sediments) was characterized by $c=1 \mathrm{MPa}, \sin \varphi=0$. Viscosity of partially molten rocks at P-T conditions above their wet solidus (Table 2) was taken as a constant $\left(10^{18}\right.$ $10^{21} \mathrm{~Pa} \mathrm{~s}$ in different numerical experiments).

[18] In our model, the presence of water affects the mantle rheology in a binary fashion inducing steplike change of the flow law from "dry" to "wet" olivine rheology (compare hydrated/serpentinized and dry mantle in Table 2). The reason for this approach is that our mantle hydration model requires saturation of the water content (up to 2 wt \%, Table 1) in the mantle before aqueous fluids can penetrate further. This creates relatively sharp changes in the water content across the hydration front [e.g., Nikolaeva et al., 2008, Figure 5] which, in turn, results in sharp changes in the rheological behavior. More sophisticated hydration models (e.g., water diffusion [Richard and Bercovici, 2009]) may result in a smoother water distribution above slabs for more gradual changes in rheology.

\section{Numerical Results}

\subsection{Basic Thermal-Chemical Structure}

[19] To investigate the effect of hydration and melting processes on 3-D dynamics of mantle wedges, we have performed in parallel three series (4 models in each) of runs with different lateral model widths $(200,400$ and $800 \mathrm{~km})$ and different lateral resolutions $(2,4$ and $8 \mathrm{~km}$, respectively). Different model widths were tested since dimensions of plumes along the trench were not known a priori. It has been found that uniformly resolved $200 \mathrm{~km}$ wide models are indeed sufficient to capture major plume morphologies and dimensions. Therefore we concentrate our further analyses on these models. We discuss below 4 numerical models with different effective viscosities of partially molten rocks (range from $10^{18}$ to $10^{21} \mathrm{~Pa} \mathrm{~s}$, see Table 4).

[20] The subducting slab retreats to the right in all of our models and the spreading center (Figures 1c and 1d) is spontaneously formed in the young left plate in response to its extension and cooling. Due to both the lateral growth of the extending overriding plate and the right shift of computational domain, the spreading center gradually approaches the left boundary of the model and then stabilizes at this boundary according to the imposed mantle weakening condition. Spreading center dynamics in our models is very similar to 2-D models of the retreating oceanic subduction [Nikolaeva et al., 2008; Gerya et al., 2008] where the entire retreating slab is present in the computational domain.

[21] In all runs, thermal-chemical partially molten plumes (Figure $1 \mathrm{~b}$ ), which are $100-300^{\circ} \mathrm{C}$ colder than the surrounding mantle (Figure 1c), develop within the first $10 \mathrm{Myr}$. The geometry and pattern of the plumes vary with time, producing very complex spatial and temporal signature. In section 3.2, we describe in detail three major types of plume development obtained in our numerical experi- 


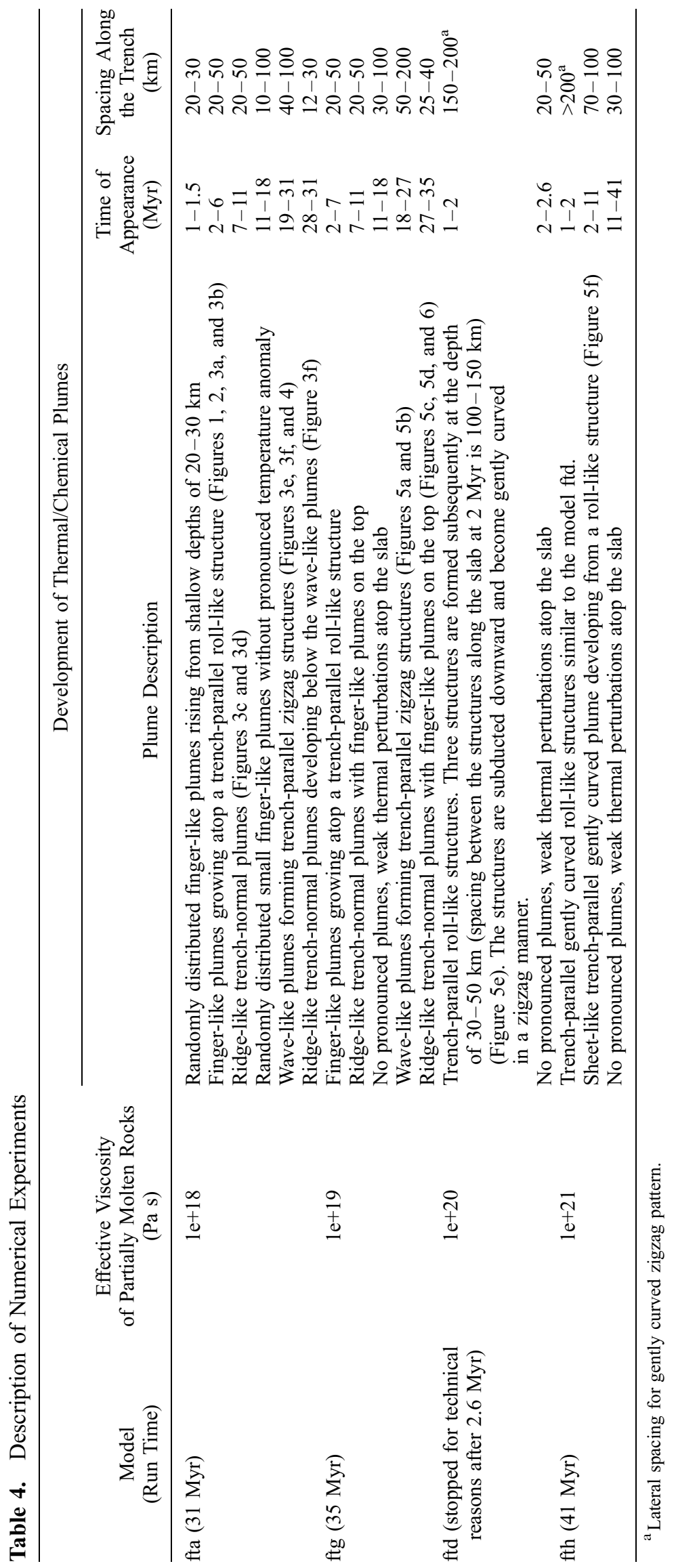



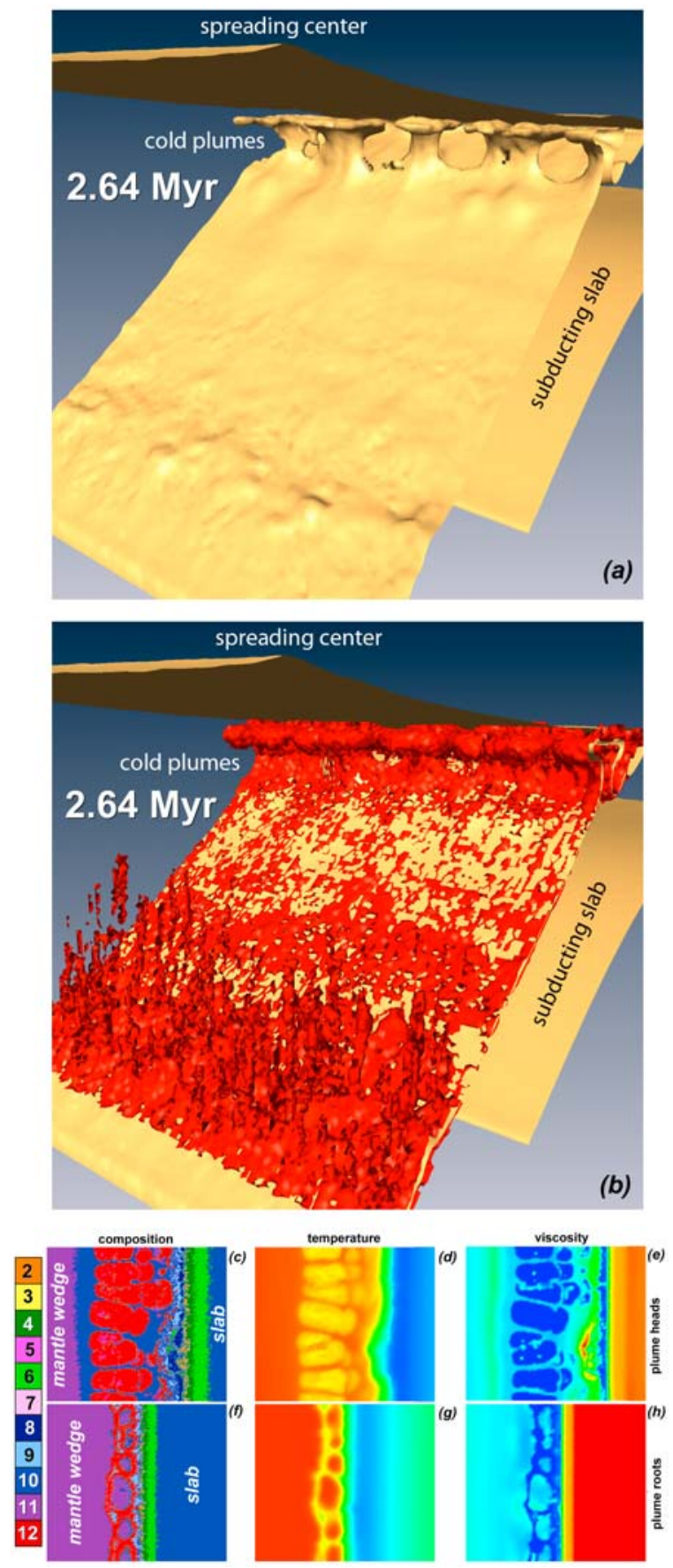

Figure 2. Mushroom-shaped thermal-chemical plumes above the subducting slab beneath a pronounced spreading center $(200 \mathrm{~km}$ wide reference model $\mathrm{fta}$ in Table 4). (a) The $1350 \mathrm{~K}$ isosurface of temperature at 2.64 Myr. (b) Same temperature isosurface (yellow) with partially molten rocks, which are responsible for plume buoyancy, shown in red. Top view of the thermal-chemical plumes (Figures 2a and $2 \mathrm{~b}$ ) including $(\mathrm{c}-\mathrm{e})$ plume heads at $30 \mathrm{~km}$ depth and (f-h) plume roots at $50 \mathrm{~km}$ depth. Figures $2 \mathrm{c}$ and $2 \mathrm{f}$ show composition, Figures $2 \mathrm{~d}$ and $2 \mathrm{~g}$ show temperature, and Figures $2 \mathrm{e}$ and $2 \mathrm{~h}$ show viscosity. The color codes are the same as in Figure 1. ments and analyze the influence of the varied model parameters on these plume patterns.

\subsection{Development of Thermal-Chemical Plumes}

\subsubsection{Model With $10^{18}$ Pa s Viscosity of Partially Molten Rocks}

[22] We choose this model (fta in Table 4) as the reference case since small-scale purely thermal convection is likely to occur when the viscosity of the LVW is $<10^{19} \mathrm{~Pa}$ s [Honda and Saito, 2003]. After initiation of retreating subduction across an imposed fracture zone [Hall and Kincaid, 2001; Nikolaeva et al., 2008], aqueous fluids from dehydration of the descending slab hydrate the overlaying mantle [Arcay et al., 2005; Gerya et al., 2006; Gerya and Yuen, 2003b; Iwamori, 1998, 2004; Schmidt and Poli, 1998], thus lowering the viscosity and density of the mantle above the slab (Figure 1d) and triggers Rayleigh-Taylor-like instabilities (Figure 1c). Compositionally buoyant hydrous plumes consisting of hydrated and molten mixed rocks (Figures 1b, 2a, and $2 b$ ) initiate from the slab and rise upward through the hot mantle wedge [Gerya et al., 2006; Gerya and Yuen, 2003b; Gorczyk et al., 2007a].

[23] Early model development (1-1.5 Myr) is characterized by the rapid retreat and descent of the initially flat slab, accompanied by the appearance of randomly distributed, finger-like plumes at depths around 20-30 km. Between 1.8 and 2.2 Myr, finger-like plumes start to align along the trench and thus forming a roll-like structure (Figure 3a). Then they become gently curved in a zigzag manner at around 2.6 Myr (Figures 2a and $3 b$ ). In Figures $2 \mathrm{c}-2 \mathrm{~h}$ we look downward on these small-scale thermal-chemical instabilities taken at depths of $30 \mathrm{~km}$ (Figures 2c-2e) and $50 \mathrm{~km}$ (Figures $2 \mathrm{f}-2 \mathrm{~h}$ ). One can observe the changes in the morphology of the diapirs as they rise upward. The individual plume heads are elongated as a flat surface perpendicular to the trench while plume roots mainly form a trench-parallel structure near the slab surface. The lateral variations in composition, temperature and viscosity are pronounced along the trench. Finger-like plume development (Figures 3a and 3b) shows the waxing and waning nature of these instabilities on a time scale of several million years. This process is similar to the "flip-flop" in the temperature structure (on the time scale around $2 \mathrm{Myr}$ ) discovered in small-scale purely thermal convection in the mantle wedge [Honda and Yoshida, 2005]. However, the temper- 

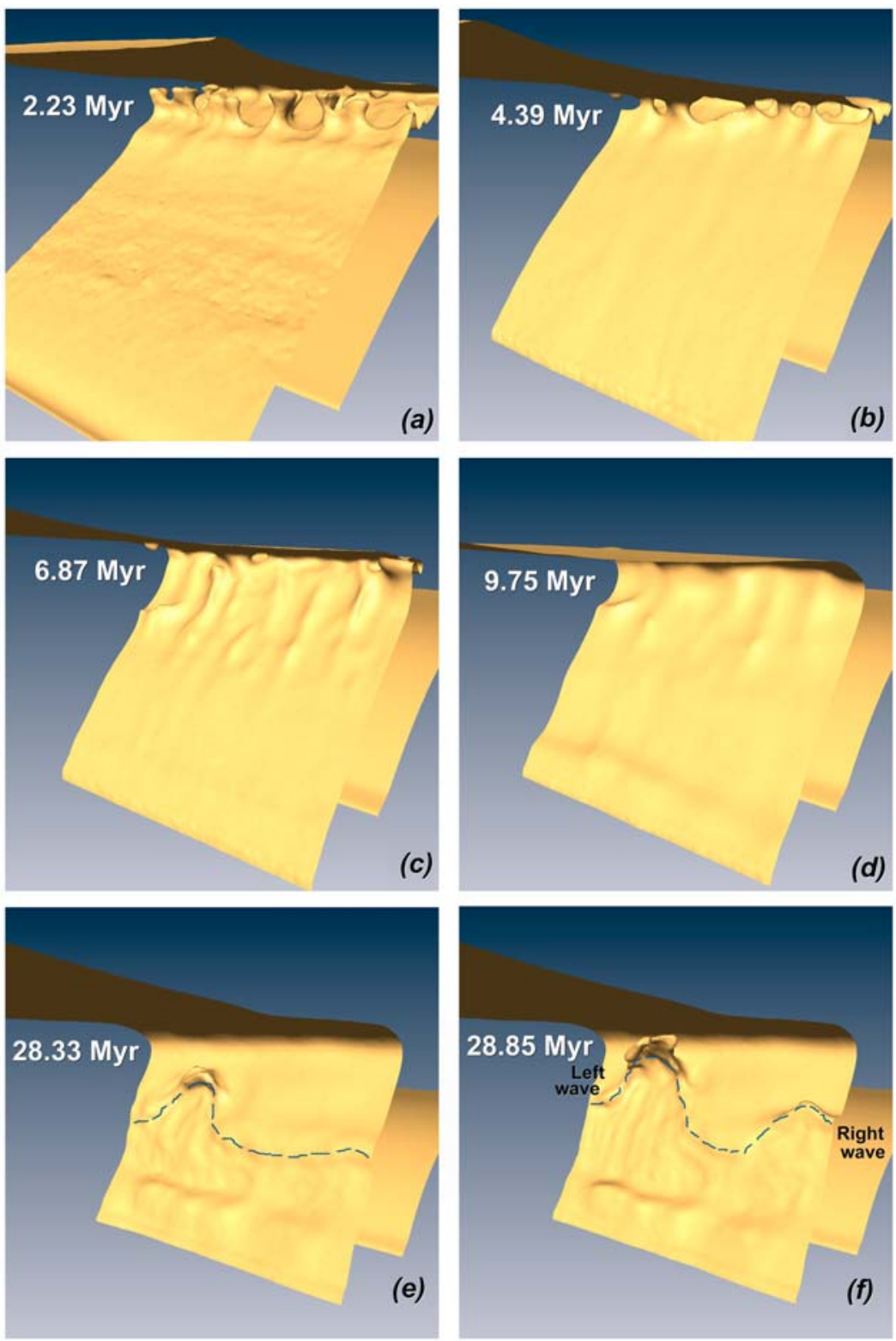

Figure 3. Growth dynamics of thermal-chemical plumes with time in reference model (model fta in Table 4) shown by the $1350 \mathrm{~K}$ isosurface. (a and b) Finger-like plumes, (c and d) trench-normal ridge-like plumes, and (e and $\mathrm{f}$ ) wave-like plumes. The zigzag patterns are marked as blue dashed lines.

ature oscillation periods in our model are notably longer (2-7 Myr), suggesting longer stable periods of thermal-chemical plumes. The pronounced thermal anomaly associated with the trench-parallel plume structure decreases with time and nearly disappears at around $7 \mathrm{Myr}$ (Figure 3c).

[24] Another notable feature is the development of regular pattern of nonmonotonic thermal-chemical trench-normal ridges with $20-50 \mathrm{~km}$ spacing around 7-11 Myr after the beginning of the experiment. This occurs after the early trenchparallel structure disappears. The thermal anoma- lies associated with these ridges are also transient and become negligible at around $11 \mathrm{Myr}$.

[25] In the time period of 11-18 Myr, randomly distributed and relatively small-scale $(2-3 \mathrm{~km}$ in diameter) finger-like instabilities appear at various depths $(50-150 \mathrm{~km})$. But no negative temperature anomaly is noticed. During this period, overriding plate cools and is thermally thickened. Also the trench retreat rate decreases, and the slab becomes significantly steeper (compare Figures $3 d$ and $3 e$ ).

[26] Finally in the late simulation period ( $>18 \mathrm{Myr})$, wave-like morphologies develop from gentle dome- 


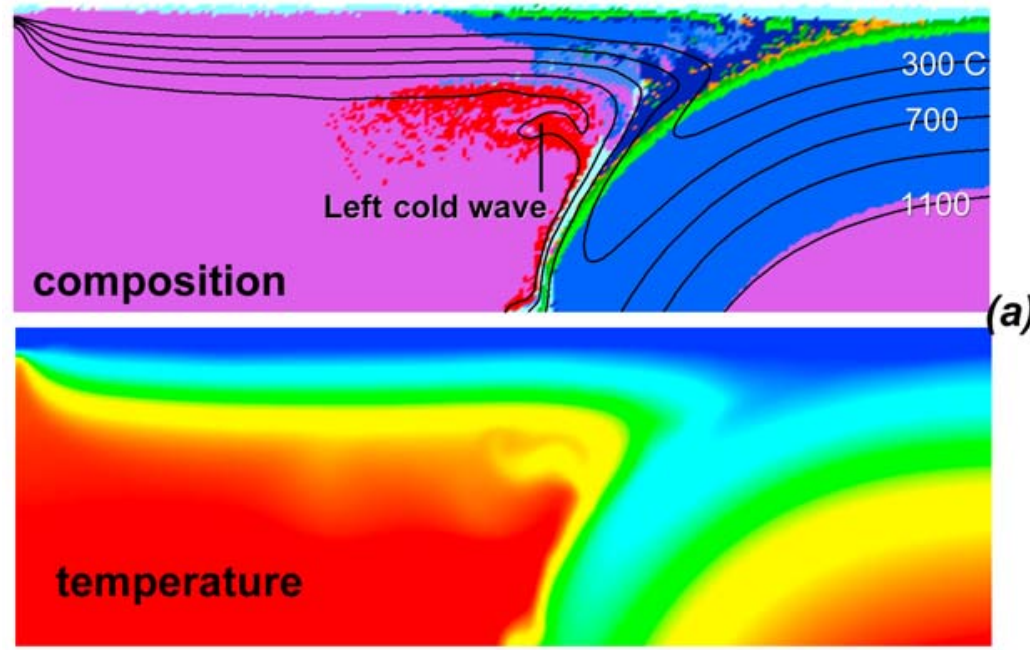

\begin{tabular}{l|l|l|l|l|l|l|l|l|l|l|l|l|l}
\hline 1 & 2 & 3 & 4 & 5 & 6 & 7 & 8 & 9 & 10 & 11 & 12 & & sediments
\end{tabular}

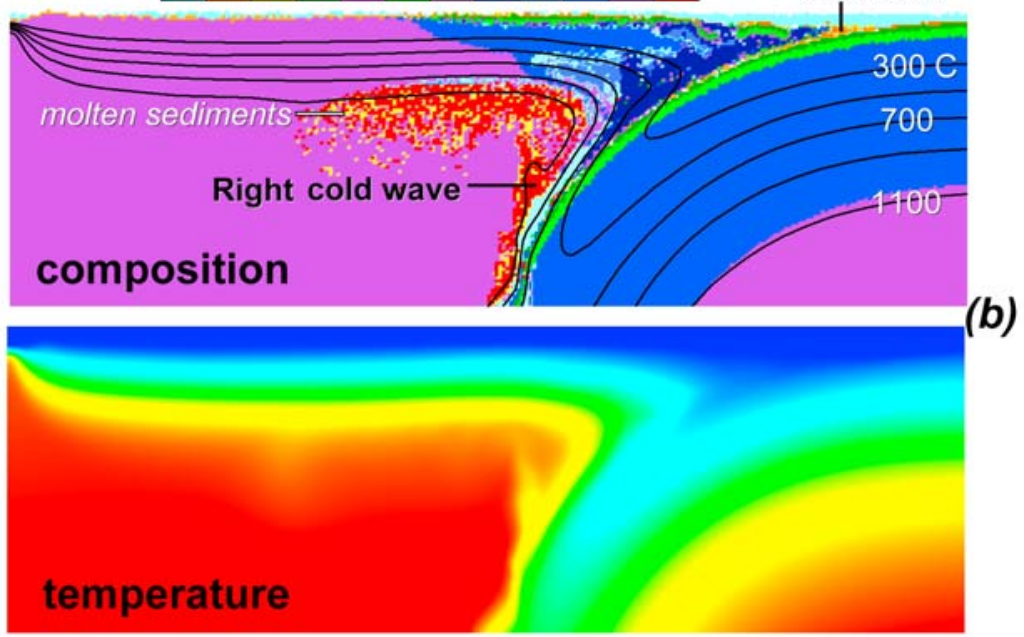

Figure 4. Cross sections for composition and temperature fields across two wave-like structures ("cold waves" [Gerya et al., 2004a, 2004c]) shown in Figure 3f at 28.85 Myr. (a) The profile in the middle of the left wave and (b) the profile in the middle of the right wave. Color codes for composition and temperature are the same as in Figure 1. Black lines are isotherms in ${ }^{\circ} \mathrm{C}$. Irrespective of the significant cooling of the overriding plate, the spreading center is stabilized at the left boundary of the model due to the imposed mantle weakening.

like perturbations atop the steep slab (Figures 3e and $3 \mathrm{f}$ ). Their initial growth rates are relatively slow, but become pronounced at about 28 Myr. Similar upward propagating wave-like instabilities were also found in the 2-D models of subduction [Gerya et al., 2004c; Nikolaeva et al., 2008] but their actual 3-D geometry remained unclear. Wavelike structures propagate upward followed by trench-normal ridges with $12-30 \mathrm{~km}$ spacing atop the slab at deeper depths $(140-175 \mathrm{~km})$. The individual waves are connected by the notable trench-parallel roll/sheet-like structure which is curved in a zigzag manner (compare Figures 3e and 3f). Details are investigated for composition and temperature fields across two wave-like structures shown in Figure $3 \mathrm{f}$ at $28.85 \mathrm{Myr}$ after the beginning of the experiment. In Figure 4, we display from the 3-D solution with approximately 38 million markers a 2-D cross section showing the compositional and temperature fields. The left cold wave is larger than the right one, but the right cold wave is adding more mixed molten rocks (including subducted sediments) into the thermally relaxed head of the bigger plume formed below the overriding plate by material addition from the previous episodes of plumes development. The slab inclination becomes steeper and steeper and the thickness of the overriding plate becomes thicker and thicker than those in the earlier stages (compare Figures 1 and 4). From this view we can discern their resemblance to the 2-D solutions [Gorczyk et al., 2007a], hydrated partially molten thermal-chemical plumes 

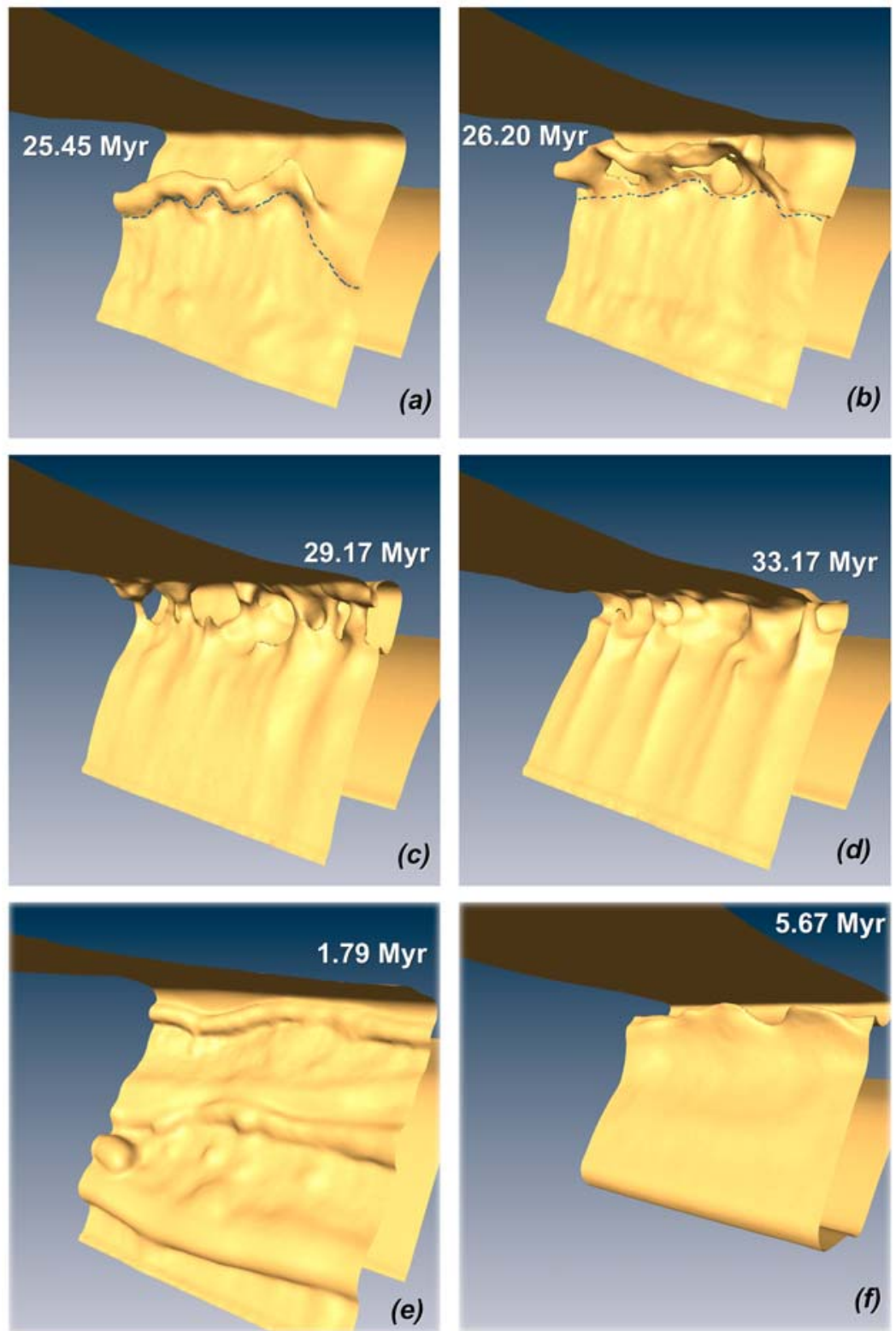

Figure 5. Dynamics of plumes in the models with increased viscosity of partially molten rocks: $(\mathrm{a}-\mathrm{d}) \eta_{\min (\mathrm{melt})}=$ $10^{19} \mathrm{~Pa} \mathrm{~s}$, (e) $\eta_{\min (\text { melt })}=10^{20} \mathrm{~Pa} \mathrm{~s}$, and (f) $\eta_{\min (\text { melt })}=10^{21} \mathrm{~Pa}$ s. Figures 5a and $5 \mathrm{~b}$ show wave structures; the zigzag patterns are marked as blue dashed lines. Figures $5 \mathrm{c}$ and $5 \mathrm{~d}$ show trench-normal ridges (ftg in Table 4). Figures $5 \mathrm{e}$ and $5 \mathrm{f}$ show roll-like structures (ftd and fth in Table 4).

are responsible for the heterogeneous composition of the mantle wedge. Also similarly to 2-D models, sediments supplied at the trench are subducted toward asthenospheric depths and are partly detached from the slab, thus typically forming rather minor fraction of the plumes (Figure $4 b$ ).

\subsubsection{Model With $10^{19} \mathrm{~Pa}$ s Viscosity of Partially Molten Rocks}

[27] In this model (ftg in Table 4), the viscosity of partially molten rocks is an order of magnitude higher than that in the reference model. The dynamics of plume development in this model is largely similar to that of the previous reference model (Table 4). The significant change is the increase of the spacing between plumes. This is in particular significant in the wave-like structures (compare Figures 3e, 3f, 5a, and 5b) and in the trench-normal ridges (compare Figures 3c, 3d, 5c, and $5 \mathrm{~d}$ ). These types of plumes also become thicker and more pronounced thermally (including 

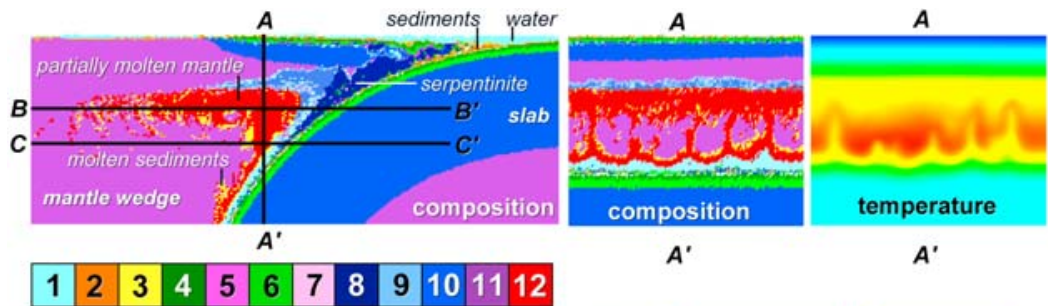

$A^{\prime}$
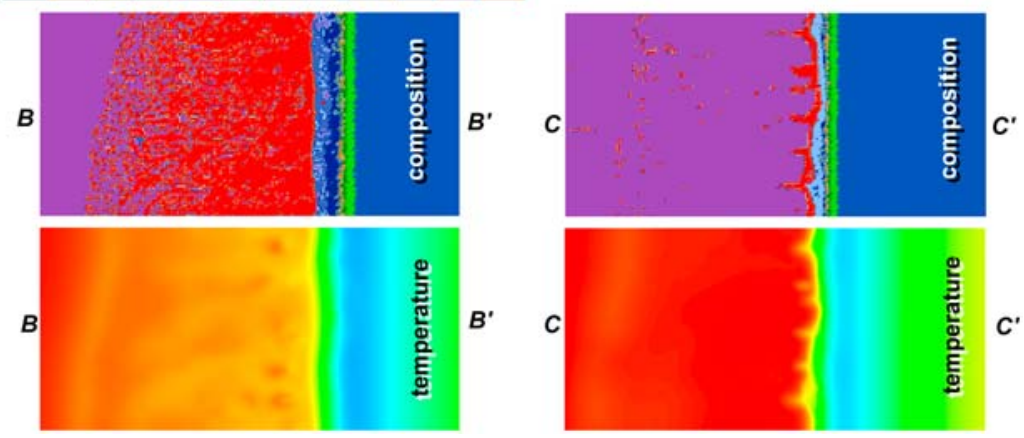

Figure 6. Cross sections for the compositional and temperature fields corresponding to the development of thermalchemical trench-normal ridges in Figure 5d. Main cross section shown in the top left corner corresponds to the first ridge from the right in Figure $5 \mathrm{~d}$. $\mathrm{AA}^{\prime}$ is the vertical cross section ( $y-z$ plane), and $\mathrm{BB}^{\prime}$ and $\mathrm{CC}^{\prime}$ are horizontal cross sections ( $x-y$ planes) at $70 \mathrm{~km}$ and $100 \mathrm{~km}$ depth, respectively. Color code for composition and temperature is the same as in Figure 1.

appearance of finger-like features) in the upper part of trench-normal ridges (Figure $5 \mathrm{c}$ ).

[28] In Figure 6, details of the composition and temperature field have been shown for the thermalchemical trench-normal ridges in Figure 5d. The ridge-like diapirs rise upward from the subducting slab and then go up to the hotter mantle wedge, and these "cold plumes" consist of a complex mixture of a partially hydrated molten rocks with both subducted rocks and primitive mantle rocks. Moreover, there are pronounced lateral variations of composition and temperature along the trench caused by compositional buoyancy according to the interval and magnitude of the ridges.

\subsubsection{Models With $10^{20}-10^{21} \mathrm{~Pa} s$ Viscosity of Partially Molten Rocks}

[29] The dynamics of these models ( $\mathrm{ftd}$, $\mathrm{fth}$ in Table 4) with 100-1000 times higher viscosity of partially molten rocks in the reference model is notably different from the previous models, characterized by notably slower subduction. The initial stage of development (1-2 Myr) is manifested by trench-parallel roll/sheet-like structures. In contrast to the lower-viscosity models, no finger-like plumes develop atop these structures that subduct together with the slab. Several structures form subsequently at depths of $30-50 \mathrm{~km}$, with the spacing around $100-150 \mathrm{~km}$ along the slab
(Figure 5e). The structures are subducted downward and become gently curved in a zigzag manner.

[30] At the later stage (2-11 Myr) strongly flattened (sheet-like) trench-parallel and gently curved plumes develop from the roll-like structures at depths of 30-50 km (Figure 5f). Lateral spacing between individual sheet-like plumes is about 70$100 \mathrm{~km}$ (Figure 5f). This is also confirmed by our numerical experiments with $400 \mathrm{~km}$ wide models. In the final stage $(>11 \mathrm{Ma})$, no pronounced plume structures appears, except weak thermal perturbations atop the slab which are caused by compositional buoyancy of subducted rocks (sediments, serpentinites).

\section{Discussion and Geophysical Implications}

\subsection{Magmatic Implications of Mantle Wedge Plumes}

[31] In this work we have confirmed the existence of cold plumes in 3-D and demonstrated the common characteristics of cold plumes in 3-D self-consistent thermal-chemical numerical experiments. Cold plumes develop as a consequence of dehydration and hydration processes in the mantle wedge during subduction, and partially molten rocks are responsible for the geometry of the plumes. The degree of melting of hydrated perido- 
tite and subducted rocks can be roughly calculated according to the following simplified linear model [Gerya and Yuen, 2003b]:

$$
\begin{gathered}
\mathrm{M}=0 \text { at } \mathrm{T}<\mathrm{T}_{\text {solidus }} ; \\
\mathrm{M}=\left(\mathrm{T}-\mathrm{T}_{\text {solidus }}\right) /\left(\mathrm{T}_{\text {liquidus }}-\mathrm{T}_{\text {solidus }}\right) \text { at } \mathrm{T}_{\text {solidus }}<\mathrm{T}<\mathrm{T}_{\text {liquidus }} ; \\
\mathrm{M}=1 \text { at } \mathrm{T}>\mathrm{T}_{\text {liquidus }}
\end{gathered}
$$

where $M$ is the volumetric fraction of melt with temperature; $T_{\text {solidus, }}, T_{\text {liquidus }}$ are wet solidus and dry liquidus temperature, respectively, at given pressure and rock composition (Table 2). The average volumetric melt production rate per unit surface $\left(\mathrm{km}^{3} / \mathrm{km}^{2} / \mathrm{Myr}=\mathrm{km} / \mathrm{Myr}\right)$ can be then computed between two time steps, by multiplying an average Lagrangian time derivative of $M$ below a given surface area $(\partial M / \partial t, 1 / \mathrm{Myr})$ to the height of the averaged column $(170 \mathrm{~km}$ in our experiments). In Figure $7 \mathrm{a}$ we have shown the spatial intensity of the melt production beneath the surface of the reference model during the 2-4 Myr after the beginning of the experiment (Figures 2, 3a, and $3 \mathrm{~b})$. Peaks of the melt production indicate individual thermal-chemical plumes. We can discern the linear structure close to the trench, and another line of peaks in linear pattern, which is approximate $200 \mathrm{~km}$ away from the trench. The former ones are mainly from the depth of 50$70 \mathrm{~km}$; the latter ones are mainly from the depth of $140-170 \mathrm{~km}$. Figure $7 \mathrm{~b}$ shows the melt productivity in time by visualizing the isosurface $\left(0.6 \mathrm{~km}^{3} / \mathrm{km}^{2} / \mathrm{Myr}\right)$ of melt production intensity. The plume-like structures are reflected by distinct "cigar-like" features that are bounded in both time and space (Figure 7b). Each "cigar" corresponds to the activity of a distinct plume that (1) increases the melt productivity during the early stage (Figure 3a) when the growing melt production is related to decompressing and heating of the rising plume material and (2) decreases the melt productivity during the later stage (Figure $3 b$ ) when the temperature, the pressure and the degree of melting stabilize inside the horizontally spreading and thermally relaxing plume.

[32] Similar "cigar-like" melt productivity patterns can also be inferred for natural subduction zones, e.g., by spatial and temporal distributions of volcanic activities in the subduction zone of northeastern Japan (Figure 8). Regarding 182 volcanoes in the northeast Honshu arc during the past $10 \mathrm{Myr}$ as volcanic activity "markers," we can interpolate the markers to the space-time grid with spatial and temporal resolution of $22 \mathrm{~km} \times 22 \mathrm{~km} \times 3 \mathrm{Myr}$ using trilinear interpolation scheme. The ages of volcanic rocks or volcanism are inferred from the chronological and stratigraphic studies [Honda and Yoshida, 2005; Honda et al., 2007]. Figure 8 shows that the density of volcanoes changes in time: formation of spatially confined clusters that remain active within certain period of time, and could be possibly related to the activity of individual thermal-chemical plumes. The spatial periodicity $(50-$ $100 \mathrm{~km})$ and the life extent $(2-7 \mathrm{Myr}$, see the lengths of "cigars" in time in Figure $8 b$ ) of such volcanic clusters are comparable to the modeled wavelength $(25-100 \mathrm{~km})$ and the growth time $(2-$ $7 \mathrm{Myr}$, see the lengths of "cigars" in time in Figure 7b) of the thermal-chemical plumes indicated by our study. The existence of two contemporaneous trench-parallel lines of melt productivity (Figure $7 b$ ) shown in our experiments is similar to the natural observations: two trench-parallel lines of Quaternary volcanic density maxima in Figure 8a (in particular, at $6 \mathrm{Ma}$ ). To explain such phenomena, Wyss et al. [2001] have proposed an additional source of fluids to be located at the top of the slab (at about $150 \mathrm{~km}$ depth). Their proposition is based on the velocity tomography in the mantle wedge above the slab, and on the mapping of earthquake size distribution within the mantle wedge. Geochemical evidence [Kimura and Yoshida, 2006] for Quaternary lavas from the NE Japan arc also shows the deeper mantle-derived rear-arc lava coming from $100-150 \mathrm{~km}$ depth.

\subsection{Physical Controls on Mantle Wedge Plume Development}

[33] Our numerical simulations show that three types of upward moving plumes occur above the slab-mantle interface: (1) the finger-like plumes forming roll/sheet-like structures parallel to the trench (Figures 2, 3a, and 3b); (2) the ridge-like structures perpendicular to the trench (Figures $3 \mathrm{c}$, $3 \mathrm{~d}, 5 \mathrm{c}, 5 \mathrm{~d}$, and 6); and (3) the flattened, wave-like instabilities propagating upward along the upper surface of the slab and forming zigzag patterns parallel to the trench (Figures 3e, 3f, 5a, and 5b). The strong tendency of forming of trench-parallel patterns (e.g., roll-like structures and sheet-like plumes, Figures 5e and 5f) in all of our models is mainly due to the planar nature of subduction which continuously and rather uniformly supplies hydrated chemically buoyant rocks along the trench (e.g., trench sediments and serpentinites formed by hydration of the overriding plate) [Gerya et al., 2002]. In contrast, the appearance of zigzag and trench-normal patterns is resulted from a nonstatic origin: the inclined subducting, 

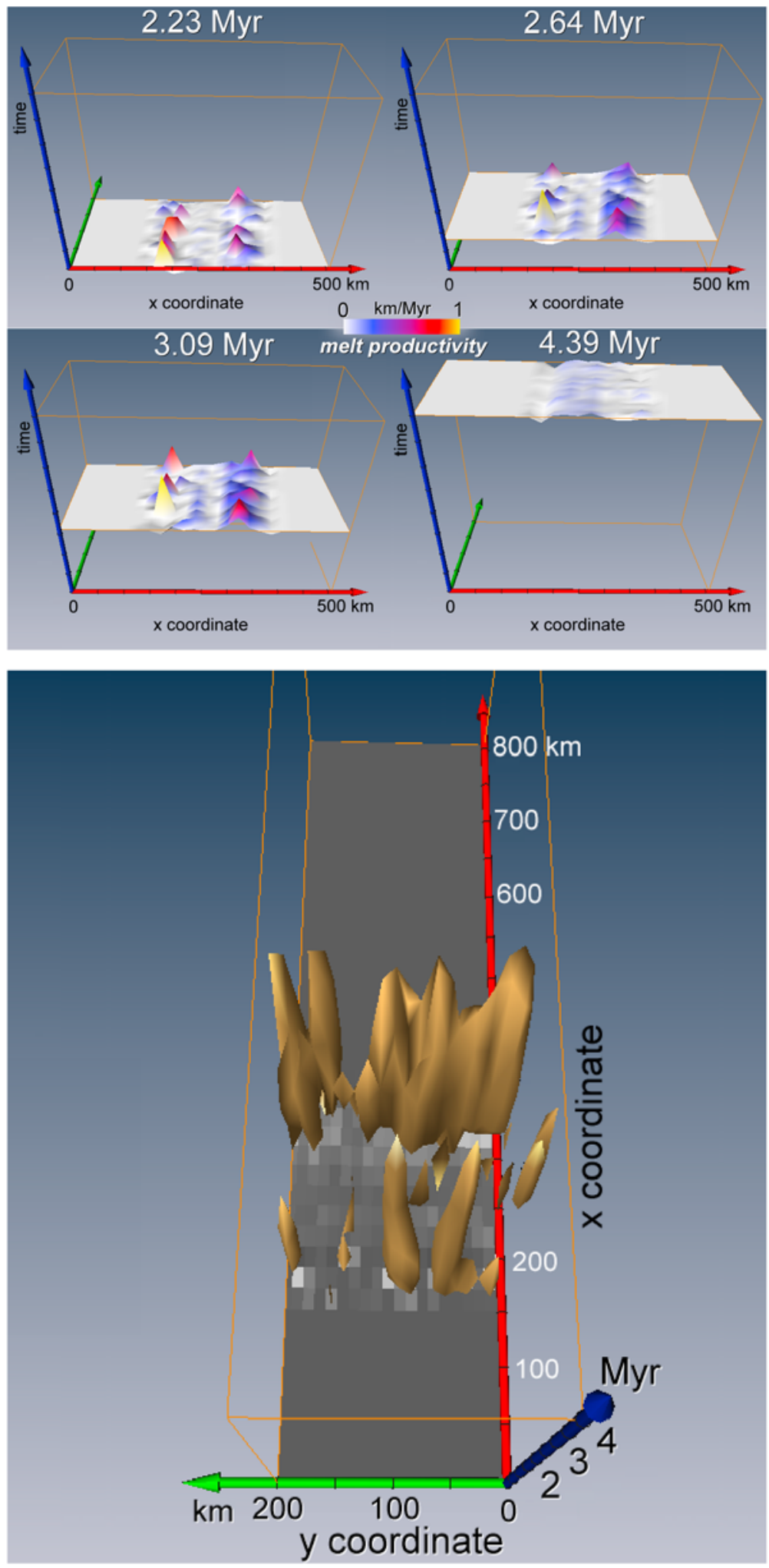

(b)

Figure 7. (a) Variations in the spatial intensity of melt production beneath the surface of the reference model in the time interval of 2-4 Myr after the beginning of experiment (Figure 3). Peaks in the melt production correspond to individual thermal-chemical plumes. (b) Isosurface corresponds to $0.6 \mathrm{~km}^{3} / \mathrm{km}^{2} / \mathrm{Myr}$, which implies crustal growth intensity of $600 \mathrm{~m} / \mathrm{Myr}$. 

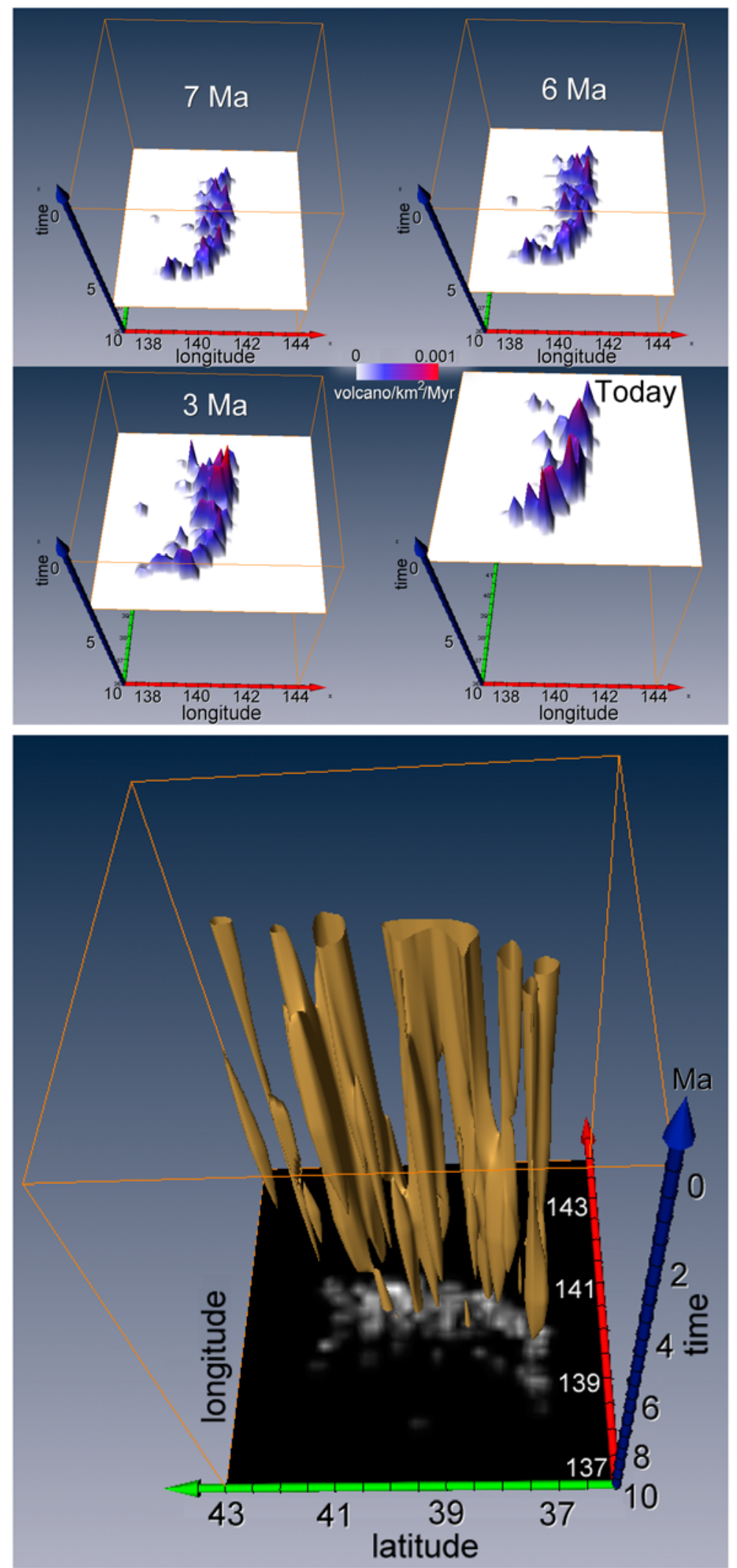

(b)

Figure 8. (a)Variations in the spatial density of volcanoes in NE Japan with their age during the past 10 Myr. (b) The isosurface corresponds to 0.0003 volcano $/ \mathrm{km}^{2} / \mathrm{Myr}$ for the observed density of volcanoes in space and time compared to the isosurface (Figure 7b) of the modeled melt production intensity at the surface. 
positively buoyant and hydrated layer formed atop the slab [Gerya and Yuen, 2003b; Richard and Bercovici, 2009]. In the layer the buoyancy force competes with the subduction drag. The buoyancy force becomes stronger in steeper slabs and promotes upward movements inside this layer (both slab-normal and slab-parallel [e.g., Gerya et al., 2004a]). On the other hand, the subduction drag tends to displace and stretch roots of the forming plume structures along the slab. This is also complemented by the development of Rayleigh-Taylor instabilities in both trench-normal [Gerya and Yuen, 2003b] and trench-parallel [Richard and Bercovici, 2009] directions. Currently no simple analytical theory is applicable to the nontrivial systems. Further efforts are needed to better understand 3-D Rayleigh-Taylor instabilities growing from the inclined and moving subduction plane.

[34] The viscosity of the partially molten plume material is the main controlling factor on the geometry and wavelength of the plumes in the mantle wedge. In particular, the lowered viscosity $\left(10^{18}-10^{19} \mathrm{~Pa} \mathrm{~s}\right)$ of partially molten rocks promotes aligned finger-like plumes from flattened to moderately inclined slabs (Figures $3 \mathrm{a}$ and $3 \mathrm{~b}$ ). These plumes are replaced by trench-parallel roll-like instabilities and sheet-like plumes (Figures 5e and $5 \mathrm{f})$ in higher-viscosity models $\left(10^{20}-10^{21} \mathrm{~Pa} \mathrm{~s}\right)$. The pronounced trench-normal ridges and the wave-like structures are only found in the lowerviscosity models. Our results also show that lower effective viscosity of the partially molten rocks helps small wavelength Rayleigh-Taylor instability atop the slab. For example, in low-viscosity models $\left(10^{18}-10^{19} \mathrm{~Pa} \mathrm{~s}\right)$, the typical spacing of finger-like plumes is about $30-45 \mathrm{~km}$ (Figures $3 \mathrm{a}$ and $3 \mathrm{~b}$ ). However, in the high-viscosity models $\left(10^{20}\right.$ $10^{21} \mathrm{~Pa} \mathrm{~s}$ ) plumes become rather sheet-like and the spacing increases to $70-100 \mathrm{~km}$ (Figure 5f). Another example is that the typical spacing of the trench-normal ridges developing behind wave-like structures in the reference model (with low viscosity of $10^{18} \mathrm{~Pa} \mathrm{~s}$ ) is around $15-25 \mathrm{~km}$ (Figures $3 \mathrm{c}$ and $3 \mathrm{~d}$ ); it increases to $25-40 \mathrm{~km}$ in the model with a higher viscosity of $10^{19} \mathrm{~Pa} \mathrm{~s}$ (Figures $5 \mathrm{c}$ and $5 \mathrm{~d}$ ). Similarly, the maximum spacing between wave-like structures increases from $100 \mathrm{~km}$ (at $10^{18} \mathrm{~Pa} \mathrm{~s}$, Figure 3f) to $200 \mathrm{~km}$ (at $10^{19} \mathrm{~Pa} \mathrm{~s}$, Figure 5a).

[35] It is also noteworthy that the geometry of the LVW in our model is very complex which is caused by water release from the slab (Figure 1) and its secondary effects including lowering viscosity and melting point in the mantle wedge.
[36] Another crucial parameter for the plume stability is the chemical density contrast caused by the compositional buoyancy of partially molten rocks [Gerya and Yuen, 2003a, 2003b]. In particular, the plume stability can be strongly affected by the buoyancy reduction related to melt extraction processes [e.g., Nikolaeva et al., 2008]. Our additional numerical experiments indicate that lowering the partially molten buoyancy to $30 \mathrm{~kg} / \mathrm{m}^{3}$ will strongly suppress plume development. Therefore, details of the plume development should be further studied by using more realistic 3-D models involving melt extraction and volcanic crust growth [Nikolaeva et al., 2008], which may help us understand precise process of the volcanoes related to subduction.

\section{Acknowledgments}

[37] We thank Paul J. Tackley and Diane Arcay for discussions. This work was supported by ETH research grants TH-0807-3, ETH-0609-2, SNF research grants 200021113672/1 and 200021-116381/1, SNF ProDoc program 4D-Adamello, and the RF President Program "Leading Scientific School of Russia" (grant 1949.2008.5) to T.V.G. David A. Yuen has been supported by VLAB project funded by National Science Foundation. Comments and suggestions from James Conder and Claire Currie are acknowledged. We also acknowledge the Editor, Peter van Keken.

\section{References}

Arcay, D., E. Tric, and M. P. Doin (2005), Numerical simulations of subduction zones: Effect of slab dehydration on the mantle wedge dynamics, Phys. Earth Planet. Inter., 149, 133-153, doi:10.1016/j.pepi.2004.08.020.

Arcay, D., M. P. Doin, E. Tric, R. Bousquet, and C. de Capitani (2006), Overriding plate thinning in subduction zones: Localized convection induced by slab dehydration, Geochem. Geophys. Geosyst., 7, Q02007, doi:10.1029/2005GC001061.

Behn, M. D., and P. B. Kelemen (2003), Relationship between seismic $\mathrm{P}$ wave velocity and the composition of anhydrous igneous and meta-igneous rocks, Geochem. Geophys. Geosyst., 4(5), 1041, doi:10.1029/2002GC000393.

Behn, M. D., G. Hirth, and P. B. Kelemen (2007), Trenchparallel anisotropy produced by foundering of arc lower crust, Science, 317(5834), 108-111.

Billen, M., and M. Gurnis (2001), A low viscosity wedge in subduction zones, Earth Planet. Sci. Lett., 193, 227-236, doi:10.1016/S0012-821X(01)00482-4.

Burg, J. P., and T. V. Gerya (2005), The role of viscous heating in Barrovian metamorphism of collisional orogens: Thermomechanical models and application to the Lepontine Dome in the Central Alps, J. Metamorph. Geol., 23, 75-95, doi:10.1111/j.1525-1314.2005.00563.x.

Carlson, R. L. (2001), The abundance of ultramafic rocks in Atlantic Ocean crust, Geophys. J. Int., 144, 37-48, doi:10.1046/j.0956-540X.2000.01280.x.

Clauser, C., and E. Huenges (1995), Thermal conductivity of rocks and minerals, in Rock Physics and Phase Relations, AGU Ref. Shelf, vol. 3, edited by T. J. Ahrens, pp. 105-126, AGU, Washington, D. C. 
Conder, J. A., and D. A. Wiens (2007), Rapid mantle flow beneath the Tonga volcanic arc, Earth Planet. Sci. Lett., 264, 299-307, doi:10.1016/j.eps1.2007.10.014.

Connolly, J. A. D. (2005), Computation of phase equilibria by linear programming: A tool for geodynamic modeling and an application to subduction zone decarbonation, Earth Planet. Sci. Lett., 236, 524-541, doi:10.1016/j.epsl.2005.04.033.

Connolly, J. A. D., and K. Petrini (2002), An automated strategy for calculation of phase diagram sections and retrieval of rock properties as a function of physical conditions, J. Metamorph. Geol., 20, 697-708, doi:10.1046/ j.1525-1314.2002.00398.x.

Davies, J. H., and D. J. Stevenson (1992), Physical model of source region of subduction zone volcanics, J. Geophys. Res., 97, 2037-2070, doi:10.1029/91JB02571.

Fluck, P., R. D. Hyndman, and C. Lowe (2003), Effective elastic thickness $T_{e}$ of the lithosphere in western Canada, J. Geophys. Res., 108(B9), 2430, doi:10.1029/2002JB002201.

Gerya, T. V. (2009), Introduction to Numerical Geodynamic Modelling, 345 pp., Cambridge Univ. Press, Cambridge, U. K., in press.

Gerya, T. V., and D. A. Yuen (2003a), Characteristics-based marker-in-cell method with conservative finite-differences schemes for modeling geological flows with strongly variable transport properties, Phys. Earth Planet. Inter, 140, 293-318, doi:10.1016/j.pepi.2003.09.006.

Gerya, T. V., and D. A. Yuen (2003b), Rayleigh-Taylor instabilities from hydration and melting propel 'cold plumes' at subduction zones, Earth Planet. Sci. Lett., 212, 47-62, doi:10.1016/S0012-821X(03)00265-6.

Gerya, T. V., and D. A. Yuen (2007), Robust characteristics method for modelling multiphase visco-elasto-plastic thermo-mechanical problems, Phys. Earth Planet. Inter., 163, 83-105, doi:10.1016/j.pepi.2007.04.015.

Gerya, T. V., B. Stöckhert, and L. L. Perchuk (2002), Exhumation of high-pressure metamorphic rocks in a subduction channel: A numerical simulation, Tectonics, 21(6), 1056, doi:10.1029/2002TC001406.

Gerya, T. V., L. L. Perchuk, W. V. Maresch, and A. P. Willner (2004a), Inherent gravitational instability of hot continental crust: Implication for doming and diapirism in granulite facies terrains, Spec. Pap. Geol. Soc. Am., 380, 97-115.

Gerya, T. V., D. A. Yuen, and W. V. Maresch (2004b), Thermomechanical modelling of slab detachment, Earth Planet. Sci. Lett., 226, 101-116, doi:10.1016/j.eps1.2004.07.022.

Gerya, T. V., D. A. Yuen, and E. O. D. Sevre (2004c), Dynamical causes for incipient magma chambers above slabs, Geology, 32, 89-92, doi:10.1130/G20018.1.

Gerya, T. V., J. A. D. Connolly, D. A. Yuen, W. Gorczyk, and A. M. Capel (2006), Seismic implications of mantle wedge plumes, Phys. Earth Planet. Inter., 156, 59-74, doi:10.1016/ j.pepi.2006.02.005.

Gerya, T. V., J. A. D. Connolly, and D. A. Yuen (2008), Why is terrestrial subduction one-sided?, Geology, 36, 43-46, doi:10.1130/G24060A.1.

Ghiorso, M. S., M. M. Hirschmann, P. W. Reiners, and V. C. Kress (2002), The pMELTS: A revision of MELTS for improved calculation of phase relations and major element partitioning related to partial melting of the mantle to $3 \mathrm{GPa}$, Geochem. Geophys. Geosyst., 3(5), 1030, doi:10.1029/ $2001 \mathrm{GC} 000217$.

Gorczyk, W., T. V. Gerya, J. A. D. Connolly, D. A. Yuen, and M. Rudolph (2006), Large-scale rigid-body rotation in the mantle wedge and its implications for seismic tomography, Geochem. Geophys. Geosyst., 7, Q05018, doi:10.1029/ $2005 \mathrm{GC} 001075$.
Gorczyk, W., T. V. Gerya, J. A. D. Connolly, and D. A. Yuen (2007a), Growth and mixing dynamics of mantle wedge plumes, Geology, 35, 587-590, doi:10.1130/G23485A.1.

Gorczyk, W., A. P. Willner, T. V. Gerya, J. A. D. Connolly, and J.-P. Burg (2007b), Physical controls of magmatic productivity at Pacific-type convergent margins: Numerical modelling, Phys. Earth Planet. Inter, 163, 209-232, doi:10.1016/ j.pepi.2007.05.010.

Hall, P. S., and C. Kincaid (2001), Diapiric flow at subduction zones: A recipe for rapid transport, Science, 292, 2472 2475, doi:10.1126/science.1060488.

Holland, T., and R. Powell (1996), Thermodynamics of orderdisorder in minerals. 2. Symmetric formalism applied to solid solutions, Am. Mineral., 81, 1425-1437.

Holland, T. J. B., and R. Powell (1998), An internally consistent thermodynamic data set for phases of petrological interest, J. Metamorph. Geol., 16, 309-343, doi:10.1111/ j.1525-1314.1998.00140.x.

Holland, T., J. Baker, and R. Powell (1998), Mixing properties and activity-composition relationships of chlorites in the system $\mathrm{MgO}-\mathrm{FeO}-\mathrm{Al}_{2} \mathrm{O}_{3}-\mathrm{SiO}_{2}-\mathrm{H}_{2} \mathrm{O}$, Eur. J. Mineral., 10, $395-$ 406.

Honda, S., and M. Saito (2003), Small-scale convection under the back-arc occurring in the low viscosity wedge, Earth Planet. Sci. Lett., 216, 703-715, doi:10.1016/S0012821X(03)00537-5.

Honda, S., and T. Yoshida (2005), Application of the model of small-scale convection under the island arc to the NE Honshu subduction zone, Geochem. Geophys. Geosyst., 6, Q01002, doi:10.1029/2004GC000785. (Correction, Geochem. Geophys. Geosyst., 6, Q06004, doi:10.1029/ 2005GC000985, 2005.)

Honda, S., M. Saito, and T. Nakakuki (2002), Possible existence of small-scale convection under the back arc, Geophys. Res. Lett., 29(21), 2043, doi:10.1029/2002GL015853.

Honda, S., T. Yoshida, and K. Aoike (2007), Spatial and temporal evolution of arc volcanism in the northeast Honshu and Izu-Bonin arcs: Evidence of small-scale convection under the island arc?, Isl. Arc, 16, 214-223, doi:10.1111/j.14401738.2007.00567.x.

Ito, E., and R. J. Stern (1986), Oxygen-isotopic and strontiumisotopic investigations of subduction zone volcanism-The case of the Volcano Arc and the Marianas Island-Arc, Earth Planet. Sci. Lett., 76, 312-320, doi:10.1016/0012-821X(86) 90082-8.

Iwamori, H. (1998), Transportation of $\mathrm{H}_{2} \mathrm{O}$ and melting in subduction zones, Earth Planet. Sci. Lett., 160, 65-80, doi:10.1016/S0012-821X(98)00080-6.

Iwamori, H. (2004), Phase relations of peridotites under $\mathrm{H}_{2} \mathrm{O}$ saturated conditions and ability of subducting plates for transportation of $\mathrm{H}_{2} \mathrm{O}$, Earth Planet. Sci. Lett., 227, $57-$ 71, doi:10.1016/j.eps1.2004.08.013.

Keleman, P. B., J. L. Rilling, E. M. Parmentier, L. Mehl, and B. R. Hacker (2004), Thermal structure due to solid-state flow in the mantle wedge beneath arcs, in Inside the Subduction Factory, Geophys. Monogr. Ser., vol. 138, edited by J. M. Eiler, pp. 293-311, AGU, Washington, D. C.

Kimura, J., and T. Yoshida (2006), Contributions of slab fluid, mantle wedge and crust to the origin of quaternary lavas in the NE Japan arc, J. Petrol., 47, 2185-2232, doi:10.1093/ petrology/eg1041.

Lee, C., and S. D. King (2009), Effect of mantle compressibility on the thermal and flow structures of the subduction zones, Geochem. Geophys. Geosyst., 10, Q01006, doi:10.1029/2008GC002151. 
Manea, M., V. C. Manea, L. Ferrari, V. Kostoglodov, and W. Bandy (2005), Tectonic evolution of the Tehuantepec Ridge, Earth Planet. Sci. Lett., 238, 64-77.

Morris, J. D., and S. R. Hart (1986), Isotropic and incompatible element constraints on the genesis of island-arc volcanics from Cold Bay and Amak island, Aleutians, and implications for mantle structure-Reply, Geochim. Cosmochim. Acta, 50, 483-487, doi:10.1016/0016-7037(86) 90202-4.

Nakajima, J., and A. Hasegawa (2003a), Estimation of thermal structure in the mantle wedge of northeastern Japan from seismic attenuation data, Geophys. Res. Lett., 30(14), 1760, doi:10.1029/2003GL017185.

Nakajima, J., and A. Hasegawa (2003b), Tomographic imaging of seismic velocity structure in and around the Onikobe volcanic area, northeastern Japan: Implications for fluid distribution, J. Volcanol. Geotherm. Res., 127, 1-18, doi:10.1016/S0377-0273(03)00155-0.

Newton, R. C., T. V. Charlu, and O. J. Kleppa (1980), Thermochemistry of the high structural state plagioclases, Geochim. Cosmochim. Acta, 44, 933-941.

Nikolaeva, K., T. V. Gerya, and J. A. D. Connolly (2008), Numerical modelling of crustal growth in intraoceanic volcanic arcs, Phys. Earth Planet. Inter., 171(1-4), 336-356, doi:10.1016/j.pepi.2008.1006.1026.

Obata, M., and E. Takazawa (2004), Compositional continuity and discontinuity in the Horoman peridotite, Japan, and its implication for melt extraction processes in partially molten upper mantle, J. Petrol., 45(2), 223-234.

Peacock, S. M. (1990), Fluid processes in subduction zones, Science, 248, 329-337, doi:10.1126/science.248.4953.329.

Plank, T., and C. H. Langmuir (1998), The chemical composition of subducting sediment and its consequences for the crust and mantle, Chem. Geol., 145, 325-394, doi:10.1016/S0009-2541(97)00150-2.

Poli, S., and M. W. Schmidt (1995), $\mathrm{H}_{2} \mathrm{O}$ transport and release in subduction zones: Experimental constraints on basaltic and andesitic systemsJ. Geophys. Res., 100, 22,29922,314, doi:10.1029/95JB01570.

Poli, S., and M. W. Schmidt (2002), Petrology of subducted slabs, Annu. Rev. Earth Planet. Sci., 30, 207-235, doi:10.1146/annurev.earth.30.091201.140550.

Powell, R., and T. Holland (1999), Relating formulations of the thermodynamics of mineral solid solutions: Activity modeling of pyroxenes, amphiboles, and micas, Am. Mineral., 84, $1-4$.

Ranalli, G. (1995), Rheology of the Earth, 2nd ed., 413 pp., Chapman and Hall, London.

Richard, G. C., and D. Bercovici (2009), Water-induced convection in the Earth's mantle transition zone, J. Geophys. Res., 114, B01205, doi:10.1029/2008JB005734.

Rupke, L. H., J. P. Morgan, M. Hort, and J. A. D. Connolly (2004), Serpentine and the subduction zone water cycle, Earth Planet. Sci. Lett., 223, 17-34, doi:10.1016/ j.eps1.2004.04.018.

Sajona, F. G., R. C. Maury, G. Prouteau, J. Cotten, P. Schiano, H. Bellon, and L. Fontaine (2000), Slab melt as metasomatic agent in island arc magma mantle sources, Negros and Batan (Philippines), Isl. Arc, 9, 472-486, doi:10.1046/j.14401738.2000.00295.x.

Schmeling, H., et al. (2008), A benchmark comparison of spontaneous subduction models-Towards a free surface, Phys. Earth Planet. Inter., 171, 198-223, doi:10.1016/ j.pepi.2008.06.028.
Schmidt, M. W., and S. Poli (1998), Experimentally based water budgets for dehydrating slabs and consequences for arc magma generation, Earth Planet. Sci. Lett., 163, 361379, doi:10.1016/S0012-821X(98)00142-3.

Staudigel, H., S. Hart, H. Schmincke, and B. Smith (1989), Cretaceous ocean crust at DSDP sites 417-418: Carbon uptake from weathering versus loss by magmatic outgassing, Geochim. Cosmochim. Acta, 53, 3091-3094, doi:10.1016/ 0016-7037(89)90189-0.

Stegman, D. R., J. Freeman, W. P. Schellart, L. Moresi, and D. May (2006), Influence of trench width on subduction hinge retreat rates in 3-D models of slab rollback, Geochem. Geophys. Geosyst., 7, Q03012, doi:10.1029/2005GC001056.

Stern, R. J. (2002), Subduction zones, Rev. Geophys., 40(4), 1012, doi:10.1029/2001RG000108.

Tamura, Y., Y. Tatsumi, D. P. Zhao, Y. Kido, and H. Shukuno (2002), Hot fingers in the mantle wedge: New insights into magma genesis in subduction zones, Earth Planet. Sci. Lett., 197, 105-116, doi:10.1016/S0012-821X(02)00465-X.

Thompson, J. B., and G. L. Hovis (1979), Entropy of mixing of sanidine, Am. Mineral., 64, 57-65.

Turcotte, D. L., and G. Schubert (2002), Geodynamics, 456 pp., Cambridge Univ. Press, Cambridge, U. K.

Ueda, K., T. Gerya, and S. V. Sobolev (2008), Subduction initiation by thermal-chemical plumes: Numerical studies, Phys. Earth Planet. Inter., 171, 296-312, doi:10.1016/ j.pepi.2008.06.032.

van Keken, P. E., and S. D. King (2005), Thermal structure and dynamics of subduction zones: Insights from observations and modeling, Phys. Earth Planet. Inter., 149, 1-6, doi:10.1016/j.pepi.2004.10.001.

van Keken, P. E., B. Kiefer, and S. M. Peacock (2002), Highresolution models of subduction zones: Implications for mineral dehydration reactions and the transport of water into the deep mantle, Geochem. Geophys. Geosyst., 3(10), 1056, doi:10.1029/2001GC000256.

Vasilyev, O. V., T. V. Gerya, and D. A. Yuen (2004), The application of multidimensional wavelets to unveiling multi-phase diagrams and in situ physical properties of rocks, Earth Planet. Sci. Lett., 223, 49-64, doi:10.1016/ j.eps1.2004.04.013.

Wei, C. J., and R. Powell (2003), Phase relations in highpressure metapelites in the system KFMASH $\left(\mathrm{K}_{2} \mathrm{O}-\mathrm{FeO}\right.$ $\mathrm{MgO}-\mathrm{Al}_{2} \mathrm{O}_{3}-\mathrm{SiO}_{2}-\mathrm{H}_{2} \mathrm{O}$ ) with application to natural rocks, Contrib. Mineral. Petrol., 145, 301-315, doi:10.1007/ s00410-003-0454-1.

White, R. W., R. Powell, and G. N. Phillips (2003), A mineral equilibria study of the hydrothermal alteration in mafic greenschist facies rocks at Kalgoorlie, Western Australia, J. Metamorph. Geol., 21, 455-468, doi:10.1046/j.15251314.2003.00454.x.

Wyss, M., A. Hasegawa, and J. Nakajima (2001), Source and path of magma for volcanoes in the subduction zone of northeastern Japan, Geophys. Res. Lett., 28, 1819-1822, doi:10.1029/2000GL012558.

Zhao, D. P., O. P. Mishra, and R. Sanda (2002), Influence of fluids and magma on earthquakes: Seismological evidence, Phys. Earth Planet. Inter., 132, 249-267, doi:10.1016/ S0031-9201(02)00082-1.

Zhao, D. P., Z. Wang, N. Umino, and A. Hasegawa (2009), Mapping the mantle wedge and interplate thrust zone of the northeast Japan arc, Tectonophysics, 467, 89-106, doi:10.1016/j.tecto.2008.12.017. 